\title{
Mechanical stress and deformation in the rotors of a high-speed PMSM and IM
}

\author{
M. E. Gerlach®, M. Zajonc, B. Ponick
}

High-speed electric machines are gaining importance in the field of traction drives and aviation due to their high power density. The evaluation of the mechanical stress in the rotor is one crucial part in the design process for this type of machines. The mechanical stress cannot be measured directly. Accordingly, a validation of the calculated mechanical stress is difficult and normally not performed. Instead of the mechanical stress, the deformation at the rotor surface can be measured using a spin test machine with distance sensors. The deformation can then be used to validate the calculation results.

In this paper, the mechanical load exerted on an IM rotor for a $60 \mathrm{~kW} / 20000 \frac{1}{\mathrm{~min}}$ high-speed electric machine and an PMSM rotor for a $75 \mathrm{~kW} / 25000 \frac{1}{\mathrm{~min}}$ high-speed electric machine is analysed in detail. The mechanical stress and the deformation are calculated and analysed using a FEM simulation model. Then, a spin test is performed on the two rotors. First, the burst speed is determined by operating two rotor samples above their defined test speed. Then, the deformation is measured at the rotor surface for different operating speeds and the defined test speed. The measurement and the simulation results are compared and discussed.

It can be shown that the two designs do not exceed the maximum mechanical stress for the defined operating range. In the deformation measurement of the IM rotor, a plastic deformation up to $\varepsilon_{\mathrm{IM}, \mathrm{pl}}=8 \mu \mathrm{m}$ and elastic deformation up to $\varepsilon_{\mathrm{IM}}$, el $=22 \mu \mathrm{m}$ can be seen. In regards to plastics, PMSM rotor expands up to $\varepsilon_{\mathrm{PMSM}} \mathrm{pl}=5 \mu \mathrm{m}$. The maximum elastic deformation of the PMSM rotor is $\varepsilon_{\mathrm{PMSM}, \text { el }}=40 \mu \mathrm{m}$. The comparison of the calculated and the measured elastic deformation shows good accordance for the two rotor types. Both models are capable of describing the deformation and the state of stress in the rotors. In burst tests, both rotors withstand rotational speeds far above the defined test speed.

Keywords: high-speed electric machines; von Mises stress; mechanical stress; deformation; overspeed test; burst test; permanent magnet machine; induction machine; machine design

\section{Mechanischer Stress und Verformung in den Rotoren einer Hochdrehzahl-PMSM und einer Hochdrehzahl-IM.}

Im Bereich der elektrischen Fahrzeug- und Flugzeugantriebe gewinnen Hochdrehzahlmaschinen aufgrund ihrer hohen Energiedichte an Bedeutung. Im Dimensionierungsprozess spielt die Bewertung der mechanischen Spannung im Rotor eine entscheidende Rolle. Die Validierung der Berechnungsergebnisse stellt eine Herausforderung dar, da die mechanische Spannung nicht direkt gemessen werden kann. Anstelle der mechanischen Spannung, kann die Verformung an der Rotoroberfläche bei einem Schleudertest mittels Abstandssensoren gemessen werden. Die Verformungen können zur Validierung des Berechnungsmodells verwendet werden und somit einen Rückschluss auf die mechanische Spannung im Rotor der Maschine geben.

In dieser Arbeit wird die mechanische Belastung in einer 60 kW/20000 $\frac{1}{\mathrm{~min}}$ Hochdrehzahl-Induktionsmaschine (IM) und einer 75 kW/25000 $\frac{1}{\mathrm{~min}}$ Hochdrehzahl-permanentmagneterregten Synchronmaschine (PMSM) untersucht. Die mechanische Spannung und die Verformung werden mittels eines FEM-Simulationsmodells berechnet und analysiert. Mit zwei Prototypen werden Schleudertests durchgeführt und die Berstdrehzahl des PMSM-Rotors und des IM-Rotors bestimmt. Danach wird an zwei weiteren Prototypen die Verformung an der Rotoroberfläche für unterschiedliche Betriebsdrehzahlen und die definierten Schleuderdrehzahlen gemessen, bevor auch für diese beiden Rotoren die Berstdrehzahl bestimmt wird. Die Berechnungs- und Messergebnisse werden anschließend miteinander verglichen und diskutiert.

Im vorgegeben Betriebsbereich liegen die berechneten mechanischen Spannungen unterhalb der vorgegebenen Materialwerte. Der IM-Rotor zeigt in der Messung eine plastische Verformung von bis $z u \varepsilon_{\mid \mathrm{M}, \mathrm{pl}}=8 \mu \mathrm{m}$ und eine elastische Verformung von bis $z u$ $\varepsilon_{\mathrm{IM}, \mathrm{pl}}=22 \mu \mathrm{m}$ auf. Der PMSM-Rotor weitet sich plastisch bis zu $\varepsilon_{\mathrm{PMSM}, \mathrm{pl}}=5 \mu \mathrm{m}$ auf, die maximale elastische Verformung beträgt $\varepsilon_{\mathrm{PMSM}, \mathrm{pl}}=40 \mu \mathrm{m}$. Der Vergleich zwischen der gemessenen und berechneten elastischen Verformung zeigt eine gute Übereinstimmung. Beide Modelle sind in der Lage, die Verformung und die mechanische Belastung im Betriebsbereich zu beschreiben. In den Schleuderversuchen erreichen die Rotoren Berstdrehzahlen, die weit über der definierten Schleuderdrehzahl liegen.

Schlüsselwörter: Hochdrehzahlmaschinen; von Mises-Stress; mechanischer Stress; Verformung; Schleudertest; Bersttest; Maschinendesign; Hochdrehzahl-PMSM und Hochdrehzahl-IM

Received December 15, 2020, accepted February 5, 2021, published online March 2, 2021

(C) The Author(s) 2021

\section{Introduction}

High speed electric machines are gaining importance not only for applications such as machine spindles, turbochargers and pumps, but also for traction drive applications for vehicles and aviation [14]. One main reason is the high power density of high speed electric machines. The development and research on SiC semiconductors, that are able to switch at higher frequencies, strengthens this trend $[5,6]$
This work was supported by the German Federal Ministry of Economic Affairs and Energy on the basis of a decision by the German Bundestag.

Gerlach, Martin Enno, Institute for Drive Systems and Power Electronics, Leibniz University Hannover, Welfengarten 1, 30167 Hannover, Germany

(E-mail: martin.gerlach@ial.uni-hannover.de); Zajonc, Maximilian, Institute for Drive Systems and Power Electronics, Leibniz University Hannover, Hannover, Germany; Ponick, Bernd, Institute for Drive Systems and Power Electronics, Leibniz University Hannover, Hannover, Germany 


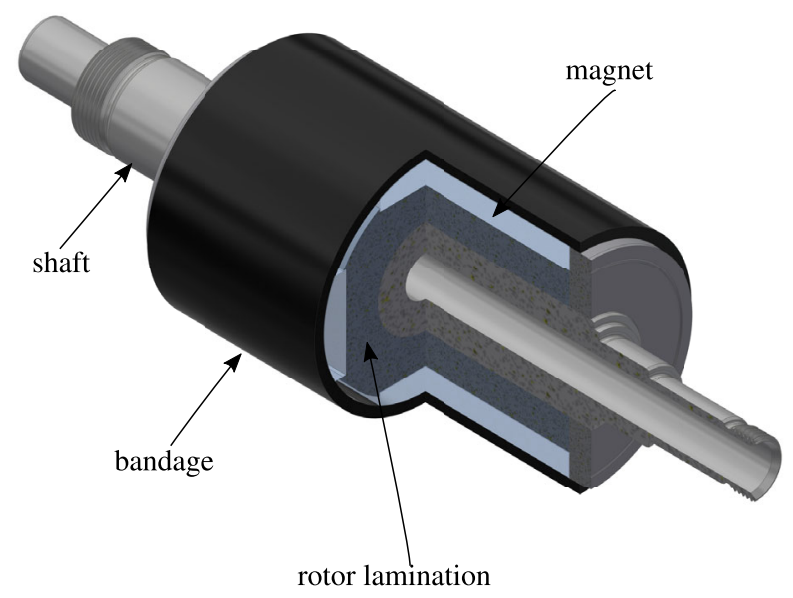

(a) PMSM rotor.

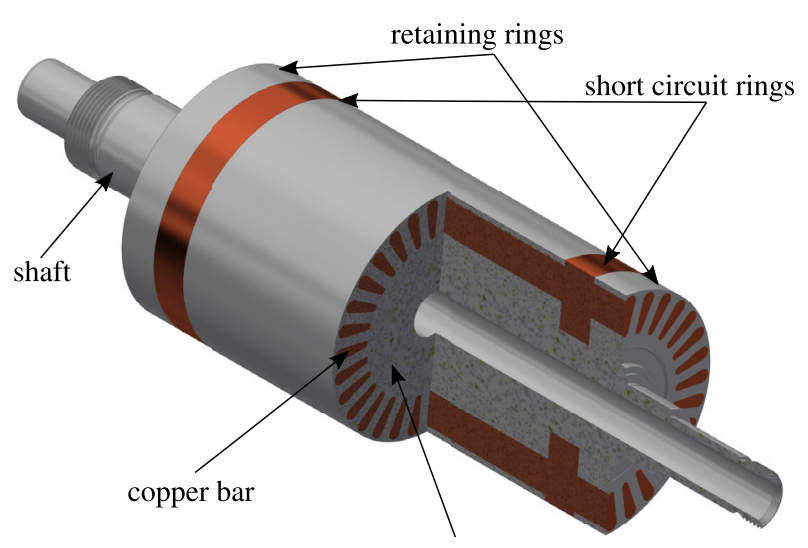

rotor lamination

(b) IM rotor.

Fig. 1. High speed PMSM with bandage and high speed IM rotor with retaining rings

The design of high speed electric machines is limited by eddy current losses in the rotor, skin and proximity effect in the stator winding, rotor dynamics, and the mechanical stress in the rotor [7-11]. The mechanical stress limits the maximum circumferential speed and accordingly the outer diameter of the rotor, the bore volume and the power of the electric machine. Thus, the calculation of the mechanical stress is a crucial part in the design process.

In a large part of the published studies concerning the mechanical stress in high speed electric machines, the mechanical stress and the deformation are calculated using FEM simulation models. But, validation by measurements is missing $[1,12-15]$. Karthaus performs a comparison for a Permanent Magnet Synchronous Machine (PMSM) with interior magnets, where he compares the calculated deformation at the rotor surface with a measurement, using laser-based distance sensors [16]. The mechanical stress can then be deduced from the measured deformations using a FEM simulation model. The mechanical stress cannot be measured directly.

In this work, this measurement method is applied to two different rotor types of a high speed electric machine and the results are compared to the results of the mechanical FEM simulation models. Additionally, burst tests are conducted on the rotors. The two rotors
Table 1. Machines data

\begin{tabular}{lll}
\hline Machine data & & \\
\hline Rotor length & $I_{2}$ & $110 \mathrm{~mm}$ \\
Air-gap & $\delta$ & $0,5 \mathrm{~mm}$ \\
Height of bandage in PMSM & $h_{\mathrm{PMSM}, \mathrm{ba}, 2}$ & $4 \mathrm{~mm}$ \\
Height of slot bridge in IM & $h_{\mathrm{IM}, \mathrm{sb}, 2}$ & $0,5 \mathrm{~mm}$ \\
Outer diameter of shaft & $D_{\mathrm{O}, \mathrm{shaft}}$ & $35 \mathrm{~mm}$ \\
Inner diameter of shaft & $D_{\mathrm{i}, \text { shaft }}$ & $15 \mathrm{~mm}$ \\
Outer diameter of rotor & $D_{\mathrm{O}, 2}$ & $81 \mathrm{~mm}$ \\
Outer diameter of stator & $D_{\mathrm{i}, 1}$ & $160 \mathrm{~mm}$ \\
Inner diameter of stator & $D_{\mathrm{O}, 1}$ & $82 \mathrm{~mm}$ \\
Number of stator slots & $N_{1}$ & 24 \\
Number of pole pairs & $p$ & 2 \\
Rated power PMSM & $P_{\mathrm{N}, \mathrm{PMSM}}$ & $75 \mathrm{~kW}$ \\
Rated power IM & $P_{\mathrm{N}, \mathrm{IM}}$ & $60 \mathrm{~kW}$ \\
Rated speed PMSM & $n_{\mathrm{N}, \mathrm{PMSM}}$ & $25000 \frac{1}{\mathrm{~min}}$ \\
Rated speed IM & $n_{\mathrm{N}, \mathrm{IM}}$ & $20000 \frac{1}{\mathrm{~min}}$ \\
Maximum speed PMSM & $n_{\max , \mathrm{PMSM}}$ & $50000 \frac{1}{\mathrm{~min}}$ \\
Maximum speed IM & $n_{\max , \mathrm{IM}}$ & $30000 \frac{1}{\mathrm{~min}}$ \\
\hline
\end{tabular}

can be seen in Fig. 1. The first rotor is a PMSM rotor with surfacemounted magnets, which are secured against centrifugal forces using a bandage. The rotor is designed for a maximum operating speed of $n_{\text {PMSM, max }}=50000 \frac{1}{\mathrm{~min}}$. The second rotor is an Induction Machine (IM) rotor with closed slots and two retaining rings, which secure the copper bars and the short-circuit ring. The maximum operating speed of the IM rotor is $n_{\mathbb{I M}, \max }=30000 \frac{1}{\mathrm{~min}}$. The two rotors are designed for the same stator. Further data of the machines is given in Table 1.

\section{Mechanical Stress in Electric Machines}

In this section, the mechanical principles and the material behaviour are explained as basis for the simulation models in Sect. 3 and the discussion of the measured deformation during the spin test in Sect. 5.

\subsection{Force, stress and deformation - Hooke's law}

A deformation $\varepsilon=\frac{\Delta l}{l}$ in a solid body occurs, when a force $\mathbf{F}$ is acting on an area $\mathbf{A}$ of a solid body. Mechanical stress

$$
\sigma=\lim _{\Delta \mathbf{A} \rightarrow 0} \frac{\mathbf{F}}{\mathbf{A}}
$$

arises in the body which is opposed to the deformation of the body [17]. The shear strain $\gamma$ and the corresponding shear stress $\tau$ occur, if the force is parallel to the area $\mathbf{A}$. If the deformation is elastic, the mechanical stress and the deformation are proportional and can be described by Hooke's law

$$
\sigma=E \cdot \varepsilon \quad \text { and } \quad \tau=G \cdot \gamma,
$$

using the proportionality constants $E$, the elastic modulus, and $G$, the shear modulus. A deformation is elastic in case the body returns into its initial form after releasing the force. In case its stays deformed after releasing the force, the deformation is called plastic $[17,18]$.

The forces that act on the body can be divided into five different types: tensile, compressive, bending, torsion and thrust forces. The forces can act in normal or in tangential direction [17]. According to the forces, different types of mechanical stress and deformations appear in the solid body. The stress is usually described by a tangential component $\tau$ and a normal component $\sigma$ (see Fig. 2 (a)). 


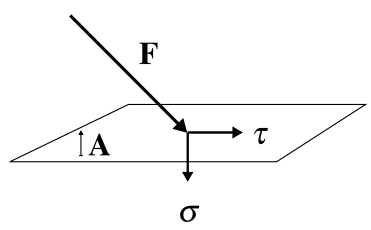

(a) Force acting on a plane A.

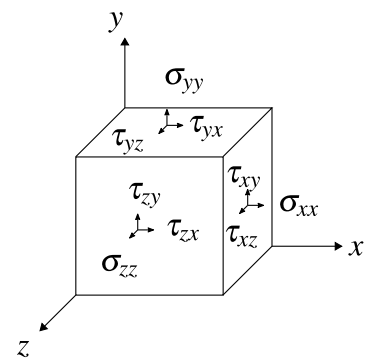

(b) Stress vectors in a cube.

\section{Fig. 2. Force and stress vectors on a plane and a cube}

The mechanical stress and the deformation in a three-dimensional body are defined by a $3 \times 3$ matrix (see Fig. 2(b))

$$
\boldsymbol{\sigma}=\left[\begin{array}{ccc}
\sigma_{x x} & \tau_{x y} & \tau_{x z} \\
\tau_{y x} & \sigma_{y y} & \tau_{y z} \\
\tau_{z x} & \tau_{z y} & \sigma_{z z}
\end{array}\right], \quad \boldsymbol{\varepsilon}=\left[\begin{array}{ccc}
\varepsilon_{x x} & \gamma_{x y} & \gamma_{x z} \\
\gamma_{y x} & \varepsilon_{y y} & \gamma_{y z} \\
\gamma_{z x} & \gamma_{z y} & \varepsilon_{z z}
\end{array}\right] .
$$

The corresponding Hooke's matrix $\tilde{\mathbb{H}}$ is a tensor of fourth order with 81 entries. To solve the resulting equation

$$
\sigma=\tilde{\mathbb{H}} \cdot \boldsymbol{\varepsilon},
$$

much computational effort is required. If the material is isotropic $\left(E=E_{x y}=E_{z x}=E_{z y}\right.$ and $\left.G=G_{x y}=G_{z x}=G_{z y}\right)$ and orthotropic, Hooke's matrix $\tilde{\mathbb{H}}$ is symmetric and can be simplified to a symmetric 9x9 matrix, according to 5, to reduce the calculation effort:

$$
\left[\begin{array}{c}
\sigma_{x x} \\
\sigma_{y y} \\
\sigma_{z y} \\
\tau_{x x} \\
\tau_{y y} \\
\tau_{z z}
\end{array}\right]=\left[\begin{array}{cccccc}
E & -\frac{E}{v} & -\frac{E}{v} & 0 & 0 & 0 \\
-\frac{E}{v} & E & -\frac{E}{v} & 0 & 0 & 0 \\
-\frac{E}{v} & -\frac{E}{v} & E & 0 & 0 & 0 \\
0 & 0 & 0 & G & 0 & 0 \\
0 & 0 & 0 & 0 & G & 0 \\
0 & 0 & 0 & 0 & 0 & G
\end{array}\right] \cdot\left[\begin{array}{l}
\varepsilon_{x x} \\
\varepsilon_{y y} \\
\varepsilon_{z z} \\
\gamma_{x x} \\
\gamma_{y y} \\
\gamma_{z z}
\end{array}\right]
$$

The entries are described by the elastic modulus $E$, the shear modulus $G$ and the Poisson ratio $v[19,20]$. The Poisson ratio $v$ is the negative ratio between the deformation in direction $x$ by length expansion in $y$-direction. Though, if the material shows an anisotropic or an asymmetric behaviour, the simplifications are not valid and the corresponding more complex Hooke's matrix needs to be solved.

\subsection{Von Mises equivalent stress}

To fully describe the state of stress in a body, at least six different stress components are needed. For simplifying the analysis of material failure, different equivalent stress theories have been developed, which map the resulting state of stress on one scalar value [18]. For steel the mostly used equivalent stress theory is the von Mises equivalent stress, also called octahedral effective stress

$$
\sigma_{v M}=\sqrt{\sigma_{x x}^{2}+\sigma_{y y}^{2}+\sigma_{z z}^{2}+\sigma_{x} \sigma_{y}-\sigma_{x} \sigma_{z}-\sigma_{y} \sigma_{z}+3\left(\tau_{x y}^{2}+\tau_{x z}^{2}+\tau_{y z}^{2}\right)} .
$$

The von Mises stress is a suitable measure to get a global overview of the state of stress in a body and to analyse the mechanical stress in a machine component.

2.3 Stress-strain diagrams for ductile and for brittle materials In this section, the material behaviour of ductile and of brittle materials is explained and the linearised material models are introduced. Ductile materials are materials such as copper, magnetic steel and construction steel. Permanent magnets, fibre-based bandages and

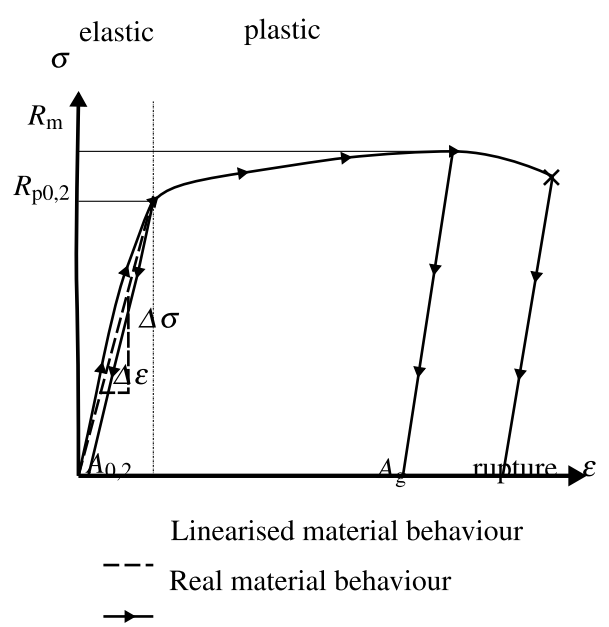

(a) Ductile material.

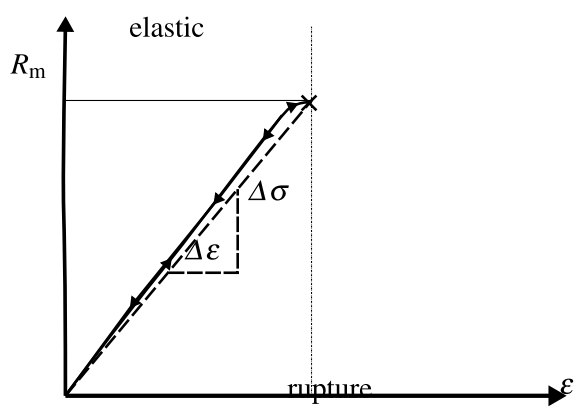

Linearised material behaviour

Real material behaviour

(b) Brittle material.

Fig. 3. Exemplary stress-strain diagram [21]

glue are brittle materials. The material behaviour can be described by stress-strain diagrams. The stress-strain diagrams for brittle and for ductile materials are shown in Fig. 3.

First, the material behaviour for ductile materials is explained (see Fig. 3 (a)): If a force is applied to the material, mechanical stress and deformation occur. The mechanical stress and the deformation are proportional until the mechanical stress reaches the yield strength $R_{\mathrm{p} 0,2}$. The yield strength $R_{\mathrm{p} 0,2}$ is defined as the mechanical stress at which a plastic deformation of $\varepsilon=0,2 \%$ remains after releasing the mechanical load. Once the yield strength is reached, the deformation increases further, while the mechanical stress increases slower. After reaching the ultimate strength $R_{\mathrm{m}}$ at the plastic deformation $A_{g}$, the stress decreases until the material breaks. As long as the mechanical stress is smaller than the yield strength $R_{\mathrm{p} 0,2}$, the deformation in the material is almost elastic. When the force is increased further, the deformation becomes strongly plastic. The material changes its internal structure and does not return into its initial state [17, 22]. To describe the material behaviour in a material model, the stress-strain diagram is simplified. The stress-strain diagram is divided into an elastic area and a plastic area, even though small plastic deformation occurs in the elastic area and vice versa. By simplifying the material model, the behaviour can be linearised and the material is described by Hooke's law with the elastic and the 
shear modulus from (2). In this work, the materials are just modelled for the elastic case since the rotors should be high-fatigue-resistant and no plastic deformation should occur.

Orthotropic materials, like fibre-based bandages, show different material properties in different spatial directions. In this case, elastic modulus, shear modulus and Poisson ratio have different values regarding the different spatial directions [23].

Brittle materials do not show a plastic deformation. If a force is applied to the material, the deformation and the mechanical stress are almost proportional to each other. Just before the material breaks at the ultimate strength $R_{m}$, the deformation becomes slightly larger related to the mechanical stress. As shown in Fig. 3 (b), the deviations are small compared to the linearised material model. Thus, the material can be described by Hooke's law with the elastic and the shear modulus according to $(2)[17,24]$.

To avoid material failure and according to ensure a high fatigue resistance of the rotors, the maximum mechanical stress occurring during the operation of an electric machine should always be in the elastic area. Therefore, safety factors are defined as

$$
\gamma=R_{\mathrm{p}} / \sigma_{\max } .
$$

These safety factors are used in Sect. 5 to validate the mechanical strength in the simulation models of the rotors $[18,25]$.

\section{Simulation model}

In this section, the FEM simulation models of the PMSM and the IM rotor are introduced. They are used in order to calculate the deformation and the mechanical stress due to centrifugal forces and thermal expansion.

The mechanical simulation model consists of the examined structure with its individual components that are allocated to the corresponding material models. Different mechanical loads are assigned to the components such as centrifugal forces or press fits. Furthermore, the contact modelling between the components is an essential part in the mechanical simulation process. According to the contact definition, the exchange of forces between the different components is defined. The contact definition is also used to simulate the press fit. If two components interfere, a force is added to the model that is acting contrary to the interference [26]. In iterative calculation steps, an equilibrium between the assigned forces in the contact and the centrifugal forces is calculated. When the result converges under a certain level of error, the simulation is finished. For the calculation, the Augmented Lagrange Algorithm is used [27, 28]. First, the simulation model of the PMSM rotor is introduced, followed by the simulation model of the IM rotor.

\subsection{PMSM rotor}

The simulation model of the PMSM machine rotor is depicted in Fig. 4, showing the mesh assembly, the boundary definitions and contact areas.

\subsubsection{Boundary and symmetry conditions}

The structure of the rotor does not change along the axial direction of the rotor. Therefore, it is sufficient to model just one magnetic sheet layer of the rotor lamination with the corresponding axial part of the shaft, the magnets and the bandage. Due to symmetry conditions, it is sufficient to simulate only one pole of the rotor, using appropriate boundary conditions. The symmetry conditions in the axial direction are enabled as friction-free bearings at top and bottom of the model, marked as B1 in Fig. 4. The symmetry conditions in radial direction are enabled as friction-free bearing on the sides of the model (see Fig. 4 (a) B2). Inside the hollow shaft, a cylindrical bearing is assigned to enable the rotation.

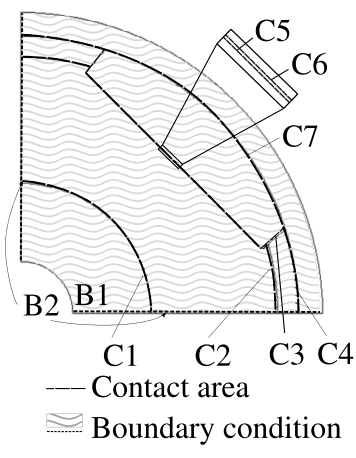

(a) Contact and boundary definitions.

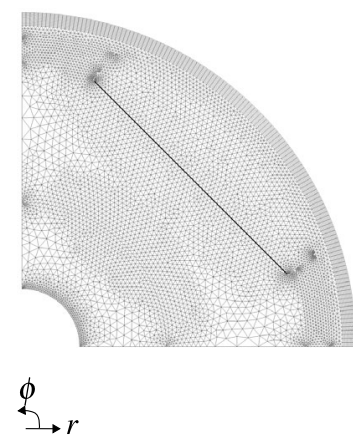

(b) Mesh assembly.
Fig. 4. Simulation model of the PMSM rotor (Designation given in Table 2)

Table 2. Contact definitions PMSM

\begin{tabular}{llll}
\hline Contact & Components & $\begin{array}{l}\text { Friction } \\
\text { coefficient }\end{array}$ & Press fit \\
\hline C1: Frictional & RL and shaft & 0,15 & $35 \mu \mathrm{m}$ \\
C2: Bonded & RL and FM & - & - \\
C3: Bonded & MA and FM & - & - \\
C4: Frictional & BA and FM & 0,15 & $210 \mu \mathrm{m}$ \\
C5: Bonded & RL and glue & - & - \\
C6: Bonded & glue and MA & - & - \\
C7: Frictional & BA and MA & 0,15 & $210 \mu \mathrm{m}$ \\
BA = bandage, FM f fill material, RL $\hat{=}$ rotor lamination, \\
MA = magnet
\end{tabular}

\subsubsection{Contact modelling}

The assigned contact definitions of the PMSM simulation model are listed in Table 2. The rotor lamination is mounted on the shaft using a press fit, enabling torque transmission. The contact is set as a frictional contact with the corresponding interference, marked as $\mathrm{C} 1$ in Fig. 4 (a). The magnets are glued in the provided magnet slots. The glue is considered as a thin layer with a height of $0,1 \mathrm{~mm}$ between magnet and rotor lamination (see Fig. 4, C5 and C6). The contacts between magnet and the glue and the rotor lamination and the glue are defined as bonded. The spaces between the magnets are filled with an epoxy resin Araldite in order to provide an even radial surface for the press fit with the bandage. The contact definition between the fill material and the rotor lamination as well as the fill material and the magnet are set as bonded (see Fig. 4 (a), C2 and C3). The bandage is mounted on the rotor with a press fit, using another frictional contact (see Fig. 4 (a), C5) to protect the magnets against centrifugal forces. The press fit of the rotor lamination, the shaft and the magnets, the fill material and the bandage lead to an initial state of stress in the rotor, which represents the state of standstill.

\subsubsection{Mesh}

Before the model can be solved, it needs to be meshed. In axial direction, it is necessary to insert at least three mesh layers, to get sufficient computational accuracy, as described in [29]. In areas with high mechanical loads as well as in areas, where the gradient of the mechanical stress is high, e.g. in the areas of the press fits and contacts, the mesh needs to be refined. The thin layer of the glue 
requires a fine mesh. Its width of $0,1 \mathrm{~mm}$ is divided into three mesh layers. Its mesh of the simulation model is shown in Fig. 4 (b)

\subsubsection{Material data and modelling}

The material used to build the rotor lamination is the soft magnetic steel M250-35A. The material of the permanent magnets is $\mathrm{Sm} 2 \mathrm{Co} 17$ and the bandage material is STS $4024 \mathrm{k}$ with $65 \% \mathrm{fi}$ bre volume. The shaft is made of the construction steel $42 \mathrm{CrMo} 4$. The corresponding material parameters are shown in Table 3. The materials of the shaft and the magnetic steel show a ductile behaviour. The permanent magnets, the bandage, the fill material and the glue are brittle materials, whereas magnets show a different behaviour for tensile and for compressive mechanical loads. The magnets can withstand compressive stress better than tensile stress. The bandage is made of glass fibre, which shows a high mechanical strength along the fibre in tangential direction, but a small mechanical strength in radial and axial direction. The fill material Araldite is a brittle material with low mechanical strength. The glue Loctite 326 shows a small ultimate strength as well. It is only used to fix the magnets on the rotor lamination in the production process. To secure the magnets against centrifugal forces, the bandage is added.

The mechanical stress of the ductile material should be below the yield strength $R_{\mathrm{p}}$. To ensure this, a safety factor $\gamma=1,05$ is defined, which allows a maximum mechanical stress $\sigma_{\max , \mathrm{RL}}=433,3 \mathrm{MPa}$ for the rotor lamination and a maximum mechanical stress $\sigma_{\text {max, shaft }}=$ 476, 2 MPa for the shaft.

The magnets are expected to be loaded with compressive stress. For Sm2Co17, a safety factor $\gamma=2$ is defined. Accordingly, the maximum mechanical compressive stress for the magnets is set to $\sigma_{\mathrm{max}, \mathrm{MA}}=400 \mathrm{MPa}$

The fibres of the bandage are brittle as well, yet the bandage, as a composite material, is considered as a ductile material. At $0,5 \cdot R_{\mathrm{m}}$, the first fibres are expected to break. This weakens the component, but does not destroy it completely. Therefore, the maximum stress for the bandage is defined to $\sigma_{\max , \mathrm{BA}}=1200 \mathrm{MPa}$. Nevertheless, fibre composites have an additional safety factor regarding the maximum relative elongation, also known as breaking elongation. The breaking elongation for the bandage material is set to $\Delta \varepsilon_{\max }=0,5 \%$

The fill material in the PMSM is not dimensioned to support any mechanical load. It is just used to create a smooth surface with the magnets to mount the bandage. Therefore, it is not further considered in the examination of the mechanical stability of the rotor

\subsubsection{Mechanical load profile and temperature}

In order to compare the results of the simulation model to the measurement results of the spin test, the load profile shown in Table 4 is applied to the simulation model. In the first calculation step, the press fit, defined by the contact definitions, is calculated for the state of standstill. The rotational speed is then increased by steps of $\Delta n=10000 \frac{1}{\mathrm{~min}}$ until the maximum operational speed in steps $n_{\max }=50000 \frac{1}{\min }$ is reached. The rotational speed is then further increased in steps of $\Delta n=1000 \frac{1}{\mathrm{~min}}$ until the test speed of $n_{\text {test }}=1,1 \cdot n_{\max }=55000 \frac{1}{\min }$ is reached. The spin test are made as a safety test, before mounting the rotors into the machine. For the spin test the ambient temperature of $T=20^{\circ} \mathrm{C}$ is defined before. Spin tests at the maximum operating temperature of the machine $T=120^{\circ} \mathrm{C}$ are not considered in this work.

\section{$3.2 \mathrm{IM}$ roto}

The simulation model of the induction machine rotor is depicted in Fig. 5. The contact areas and boundary definitions are shown as well as the mesh assembly of the simulation model.
Table 4. Mechanical load profile for the PMSM and the IM simulation model

\begin{tabular}{lll}
\hline \multirow{2}{*}{ Calculation step } & \multicolumn{2}{l}{ Rotational speed $n$ in $1 /$ min } \\
\cline { 2 - 3 } & IM & PMSM \\
\hline 1 & 0 (press fit) & 0 (press fit) \\
2 & 5000 & 5000 \\
3 & 10000 & 10000 \\
4 & 15000 & 20000 \\
5 & 20000 & 30000 \\
6 & 30000 & 40000 \\
7 & 31000 & 45000 \\
8 & 32000 & 50000 \\
9 & 33000 & 51000 \\
10 & - & 52000 \\
11 & - & 53000 \\
12 & - & 54000 \\
13 & - & 55000 \\
Rotor temperature: $T=20^{\circ} \mathrm{C}$ & \\
\hline
\end{tabular}

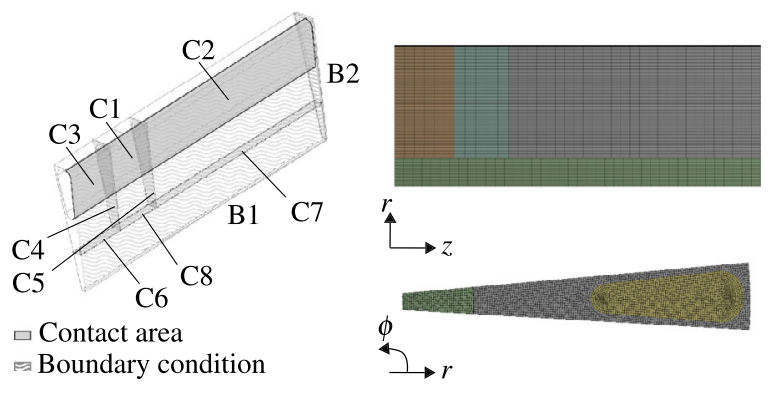

(a) Contact and boundary defini-

(b) Mesh tions.

assembly.

Fig. 5. Simulation model of the IM rotor (Designation given in Table 5)

\subsubsection{Boundary and symmetry conditions}

Due to symmetry conditions, it is sufficient to simulate only a part of the rotor using appropriate boundary conditions. Along the circumference, the structure is repeated with the number of rotor slots, in this case $N_{2}=30$. Therefore, only a $1 / 30$ of the rotor needs to be simulated. Along the axial direction, another symmetry condition can be found. The short-circuit ring and the retaining ring on both sides are identical and accordingly just half the length of the rotor needs to be simulated. To consider these symmetry conditions, the surfaces on which the model is mirrored need to be friction-free bearings (see Fig. 5 (a), B1 and B2). Inside the hollow shaft, a cylindrical bearing is assigned to enable the rotation of the model.

\subsubsection{Contact modelling}

There are multiple contact areas in the simulation model that are listed in Table 5 and can be seen in Fig. 5 (a) marked with C1-C7. The copper bars are first inserted into one short-circuit ring and then brazed together. Therefore, the contact definition between the copper bars and the short-circuit ring is set to bonded. The assembly is then inserted into the rotor lamination. On the other side, the second short-circuit ring is inserted and brazed with the copper bars. The retaining rings have slots for the copper bars and are plugged on the ends in order to secure the short-circuit rings against centrifugal forces. The contacts between the copper bars and the rotor 
Table 3. Material data of the PMSM [30-35]

\begin{tabular}{|c|c|c|c|c|c|c|}
\hline Component & Magnet & Rotor lamination & Glue & Fill material & Bandage & Shaft \\
\hline Material & $\operatorname{Sm} 2 \mathrm{Co} 17$ & M250-35A & Loctite 326 & Araldite & STS40 24k & $42 \mathrm{CrMo} 4$ \\
\hline$\alpha$ in $1 / K$ & $1 \cdot 10^{-5}$ & $1,28 \cdot 10^{-5}$ & $8 \cdot 10^{-5}$ & - & $6,31 \cdot 10^{-7}$ & $1,1 \cdot 10^{-5}$ \\
\hline$E$ in $\mathrm{GPa}$ & 150 & 185 & 300 & 4,5 & $12,49(r z) / 145,82(\phi)$ & 210 \\
\hline$\rho$ in $\mathrm{kg} / \mathrm{m}^{3}$ & 8400 & 7600 & 1600 & 1600 & 1550 & 7720 \\
\hline$v$ & 0,27 & 0,28 & 0,3 & 0,125 & $0,257(r \phi) / 0,019(\phi z) / 0,352(r z)$ & 0,3 \\
\hline$R_{\mathrm{p}}$ in $\mathrm{MPa}$ & - & 455 & - & - & - & 500 \\
\hline$R_{\mathrm{m}}$ in $\mathrm{MPa}$ & $35(+), 800(-)$ & 575 & 34 & - & $2400(\phi)$ & 825 \\
\hline
\end{tabular}

Table 5. Contact definitions IM

\begin{tabular}{llll}
\hline Contact & Components & Friction coefficient & Press fit \\
\hline C1: Bonded & CB and SCR & - & - \\
C2: Frictional & CB and RL & 0,15 & - \\
C3: Frictional & CB and RR & 0,15 & - \\
C4: Friction free & SCR and RL & 0 & - \\
C5: Friction free & SCR and RR & 0 & - \\
C6: Frictional & RR and shaft & 0,15 & $16 \mu \mathrm{m}$ \\
C7: Frictional & RL and shaft & 0,15 & $16 \mu \mathrm{m}$ \\
C8: Friction free & SCR and shaft & 0 & -
\end{tabular}

$\mathrm{CB} \hat{=}$ copper bar, $\mathrm{SCR} \hat{=}$ short-circuit ring, $\mathrm{RR} \hat{=}$ retaining ring, $\mathrm{RL} \hat{=}$ rotor lamination

lamination as well as the contact to the retaining ring are defined as frictional contacts. The contacts of the short-circuit rings to the rotor lamination and to the retaining ring are set to frictionless contacts, since the retaining ring, the short-circuit ring and the rotor lamination are just placed side by side and can move independently. The assembly is then mounted on the shaft. To ensure a connection that is able to transmit the torque, a press fit between the rotor lamination and the shaft is used. The contact is set to be a frictional contact with this press fit. The retaining ring is fixed with the same contact definition. The short-circuit ring is just mounted on the shaft without using a press fit and is kept into position by the rotor lamination and the retaining ring. The contact between the short-circuit ring and the shaft is accordingly defined as frictionless contact.

\subsubsection{Mesh}

To calculate the FEM simulation model, the geometry needs to be divided into a mesh. The used mesh is depicted in Fig. 5 (b). The mesh consists of oktaeder and tetraeder elements. The mesh is refined in the area of the slot bridges and the teeth of the rotor, since the biggest gradient in the mechanical stress is expected in these areas.

\subsubsection{Material data and modelling}

In Table 6, the materials of the IM rotor components are listed. The copper bars and the short-circuit rings are made from two different copper alloys. The copper alloy of the short-circuit ring has a higher yield strength. The rotor lamination is made of the soft magnetic steel M250-35A, which is distinguished by a high yield strength compared to commonly used magnetic steel. The rotor lamination has different material behaviours in radial and in axial direction due to insulation between the magnetic sheets [36]. Therefore, a different Elastic Modulus is defined for the xy-direction and for the $z$-direction. The retaining rings and the shaft are made from two different constructions steels, which show the highest yield strength of the materials used. The data of Table 6 are used to build the material models for the simulation model. The materials used have a ductile behaviour and are just defined for the elastic area. Plastic deformation is not considered, since the deformation should be elastic over the whole speed range. The mechanical stress should be below the yield strength $R_{\mathrm{p}}$. To ensure this, a safety factor $\gamma=1,05$ is defined, which allows a maximum mechanical stress $\sigma_{\max }=433,3 \mathrm{MPa}$ (see Sect. 2).

\subsubsection{Mechanical load profile and temperature}

The load profile is set similar to the earlier introduced load profile of the PMSM and can be seen in Table 4. The rotational speed is increased in steps of $\Delta n=5000 \frac{1}{\mathrm{~min}}$ until the maximum operational speed of $n_{\max }=30000 \frac{1}{\min }$ is reached. The rotational speed is then further increased in steps of $\Delta n=1000 \frac{1}{\mathrm{~min}}$ until the test speed of $n_{\text {test }}=1,1 \cdot n_{\max }=33000 \frac{1}{\min }$ is reached. The temperature is set to the ambient temperature of $T=20^{\circ} \mathrm{C}$ to be able to compare the results to the measurement results of the spin test.

\section{Measurement Setup}

The expansion of the rotor is determined using a spin test, that measures the deformation of the rotor surface for different rotational speeds. The measurement is similar to the setup used in [16]

\subsection{Test assembly}

The test bed used to perform the spin test is shown in Fig. 6. It consists of an electric motor connected to a gear box which accelerates the rotor specimen on the defined speed. The specimen is mounted to the gearbox on the upper part of the rotor. The lower part of the rotor is mounted to a safety bearing. The whole assembly is placed in a burst protection ring, which protects the surrounding from the rotating specimen.

\subsection{Sensor information and positioning}

The used distance sensors operate on a capacitive measurement principle. The accuracy of the measurements depends strongly on the measurement assembly and the used materials of the test specimen. The accuracy of the sensors is specified better than $\Delta \varepsilon=1 \mu \mathrm{m}$. To examine the measurement accuracy during the measurement, the deformation is measured three times for each speed. The measurement accuracy can be determined by comparing the three deformation values. The measurement accuracy in the used test assembly is smaller than $\Delta \varepsilon=0,5 \mu \mathrm{m}$. To reduce the error due to measurement accuracy further, the deformation is averaged over the three measurements for each speed step. In the following the measured deformation at one speed is referred as the mean values of the three measurements

The distance sensors are placed at defined positions. The IM rotor is measured at two axial positions. Position 1 is in the middle of the 
Table 6. Material data of the IM $[30,31,35,37,38]$

\begin{tabular}{llllll}
\hline Component & Copper bar & Short-circuit ring & Rotor lamination & Retaining ring & Shaft \\
\hline Material & $E$-Cu57 & CuCr1Zr & M250-35A & 34 CrNiMo6 & $42 \mathrm{CrMo4}$ \\
$\alpha$ in $1 / \mathrm{K}$ & $1,68 \cdot 10^{-5}$ & $1,8 \cdot 10^{-5}$ & $1,28 \cdot 10^{-5}$ & $1,21 \cdot 10^{-5}$ & $1,1 \cdot 10^{-5}$ \\
$E$ in $\mathrm{GPa}$ & 110 & 190 & $185(\mathrm{r} \phi) / 90(\mathrm{z})$ & 210 & 210 \\
$\rho$ in $\mathrm{kg} / \mathrm{m}^{3}$ & 8930 & 8910 & 7600 & 7730 & 7720 \\
$\nu$ & 0,34 & 0,34 & 0,28 & 0,3 & 0,3 \\
$R_{\mathrm{p}}$ in $\mathrm{MPa}$ & 180 & 310 & 455 & 800 & 500 \\
$R_{\mathrm{m}}$ in $\mathrm{MPa}$ & 300 & 550 & 575 & 900 & 825 \\
+ & marks a tension & &
\end{tabular}

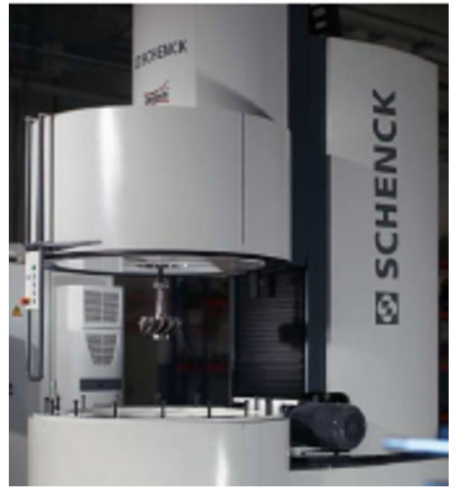

Fig. 6. Spin test machine of the company Schenck in Darmstadt, Germany

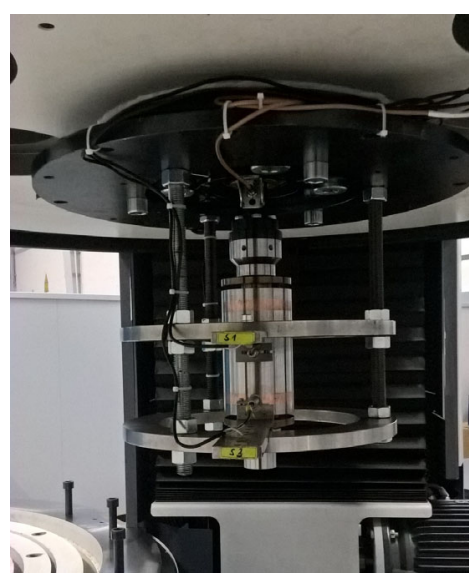

(a) Measurement assembly.

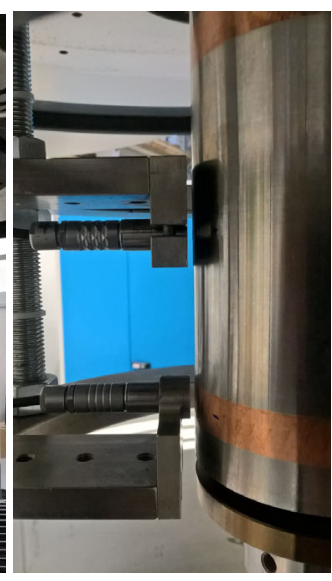

(b) Sensor positions.
Fig. 7. Test setup

axial length and position 2 is set in the middle of the short-circuit ring. The PMSM rotor is measured just at position 1, since the rotor has the same structure along the axial length. The positioning of the sensors can be seen in Fig. 7 .

\subsection{Rotor specimen}

The analysed rotor specimen are mounted on a modified shaft. The shaft is provided with the corresponding mounting to contact the rotor specimen to the spinning machine. The rotor specimen are shown in Fig. 8. Two rotor samples of each type are analysed. First, the burst speed for PMSM Rotor 1 and IM Rotor 1 is determined.

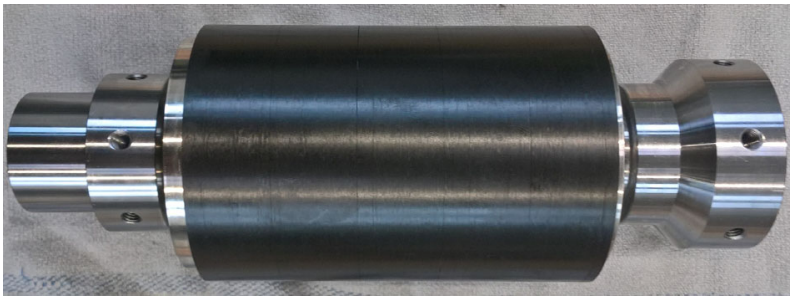

(a) PMSM rotor with bandage.

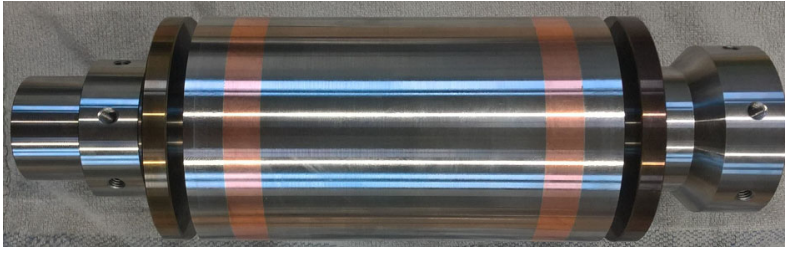

(b) IM rotor with retaining rings.

Fig. 8. Rotor samples

Then, the deformation measurements are carried out for PMSM Rotor 2 and IM Rotor 2, before the two rotors are also conducted a burst test.

\subsection{Load profile}

Different tests are carried out to analyse the mechanical strength and the deformation of the rotor specimen. First, the burst tests of the IM and the PMSM rotor are made to validate the mechanical strength of the rotors.

Then, the deformation is measured for a predefined load profile, that can be seen in Fig. 9. The load profile is similar to the load profile of the simulation (see Sect. 3). The rotational speed is raised in steps of $\Delta n_{\mathrm{PMSM}}=10000 \frac{1}{\mathrm{~min}}$ and $\Delta n_{\mathrm{IM}}=5000 \frac{1}{\mathrm{~min}}$, respectively. Between the steps, the rotor is decelerated to $n=1000 \frac{1}{\mathrm{~min}}$. The rotational speeds are kept for $\Delta T=2,5 \mathrm{~min}$. Three measurements are carried out for each step. This measurement method allows us to distinguish the elastic and the plastic deformation of the specimen by comparing the deformation at a certain rotational speed $n$ to the previously measured deformation at $n=1000 \frac{1}{\mathrm{~min}}$. After the maximum speed is reached, the distance measurement is removed and the two rotors are subjected to a burst test as well.

\section{Results and Discussion}

In this section, the results of the simulation model and the spin test are presented. In Sect. 5.1, von Mises stress is used to analyse the mechanical stress in the rotor for different rotational speeds. The calculated deformation at the rotor surface is then compared to the measurement results of the spin test in Sect. 5.2. The results are 


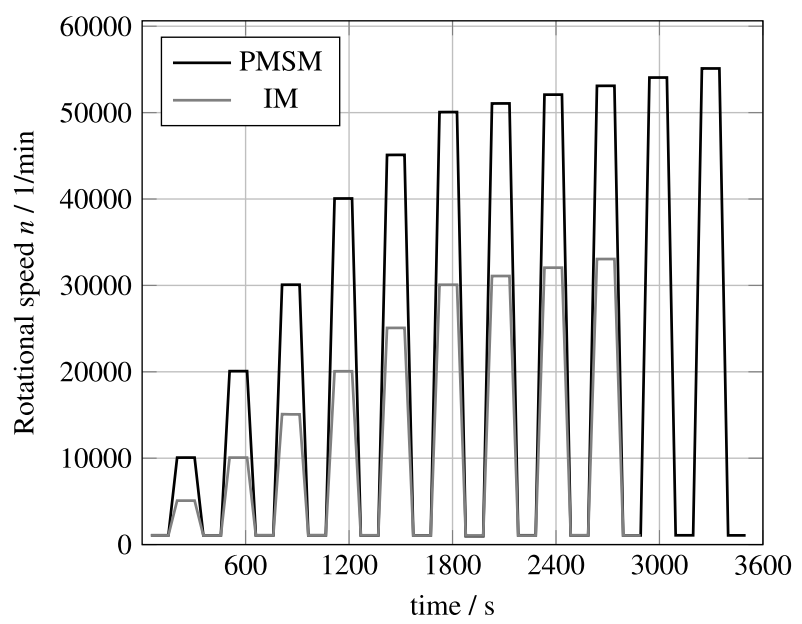

Fig. 9. Load profile of the spin test

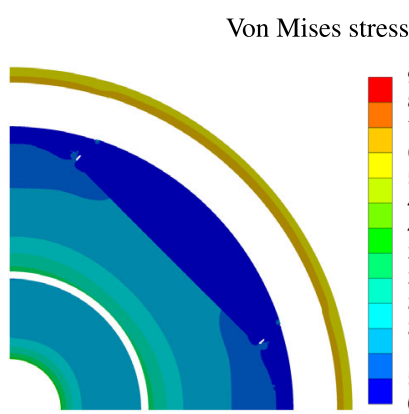

(a) $\mathrm{n}=01 / \mathrm{min}$, standstill.

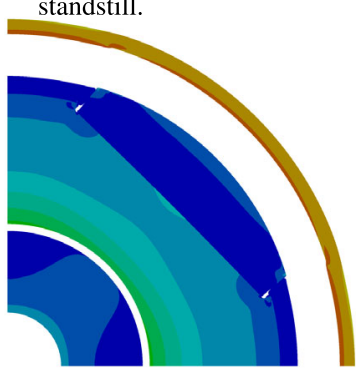

(c) $\mathrm{n}=500001 / \mathrm{min}$, max. operational speed.

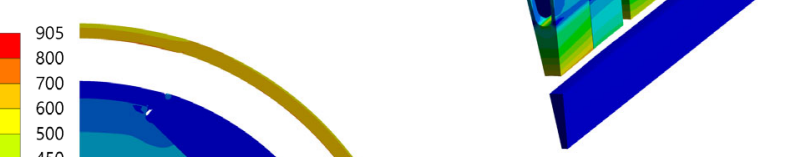

c) $\mathrm{n}=30000 \mathrm{rpm}$, max. rotational speed.
Von Mises stress in MPa

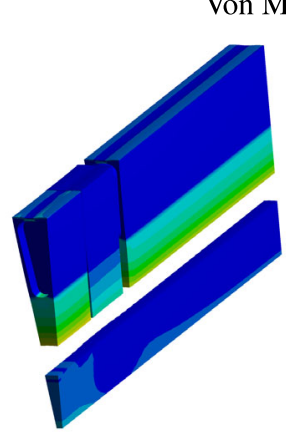

a ) $\mathrm{n}=0 \mathrm{rpm}$,

stand still

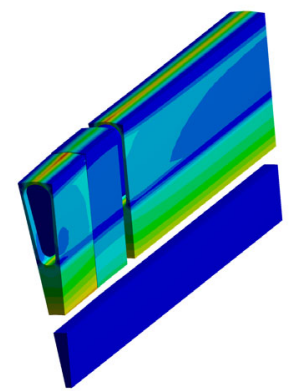

\begin{tabular}{|l|l|}
\hline 460 \\
430 \\
400 \\
\hline 370 \\
\hline 340 \\
\hline 310 \\
\hline 280 \\
\hline 250 \\
\hline 220 \\
190 \\
160 \\
130 \\
100 \\
0
\end{tabular}

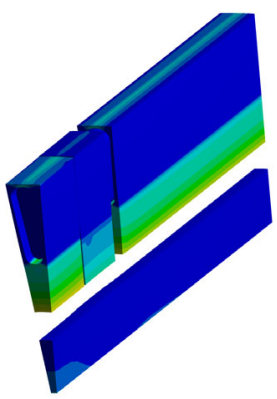

b) $\mathrm{n}=15000 \mathrm{rpm}$.

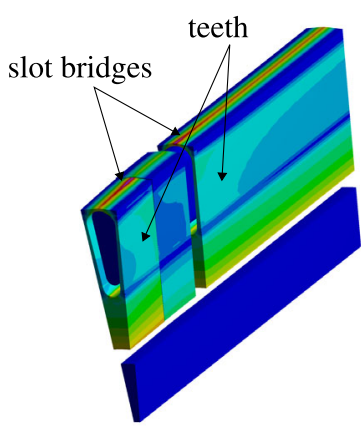

d) $\mathrm{n}=33000 \mathrm{rpm}$, spin speed.
Fig. 11. Von Mises stress in the IM rotor (scaling factor 100)

The stress increases up to $\sigma_{\mathrm{vM}, R L, n_{0}}=332 \mathrm{MPa}$ and $\sigma_{\mathrm{vM}, \text { shaft, } n_{0}}=$ $370 \mathrm{MPa}$. Shrinking the bandage on the fill material and the magnets results in a large expansion of the bandage. Accordingly, the von Mises stress in the bandage is increased up to $\sigma_{\mathrm{vM}, \mathrm{BA}, n_{0}}=$ $679 \mathrm{MPa}$. The stress in the fill material and at the outer diameter of the rotor lamination is relatively small. The magnets show a mechanical stress of $\sigma_{\mathrm{VM}, \mathrm{MA}, n_{0}} \approx 40 \mathrm{MPa}$ due to the press fit. At the magnet edges, the mechanical stress is even higher. When the rotor is accelerated, the mechanical stress in the rotor yoke increases while the stress in the shaft decreases. At $n=50000 \frac{1}{\mathrm{~min}}$, the maximum von Mises stress in the rotor lamination is $\sigma_{\mathrm{VM}, \mathrm{RL}, n_{0}}=365,5 \mathrm{MPa}$ and is within the permissible mechanical stress defined in Sect. 3 .

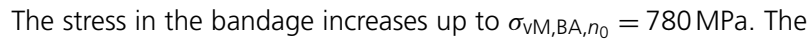
magnets are pressed on the bandage and a small mechanical stress of $\sigma_{\mathrm{VM}, \mathrm{MA}, n_{0}} \approx 50 \mathrm{MPa}$ arises at the outer contour of the magnets. Since the mechanical stress at the magnets is dominated by a compressive stress component, the magnets do not break (see Table 3). At test speed (see Fig. 10 (d)), the von Mises stress in the bandage

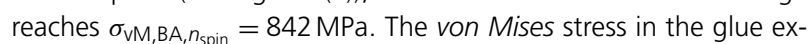
ceeds at some positions the ultimate strength. The mechanical load in the magnets increases up to $\sigma_{\mathrm{VM}, \mathrm{MA}, n_{\text {spin }}} \approx 80 \mathrm{MPa}$. In the analysed speed range, the mechanical stress in the components is still within the defined limits of the materials, as described in Sect. 3. For the bandage, the maximum deformation in radial direction needs to be examined. The elongation in tangential direction is $\Delta \varepsilon=0,242 \mathrm{~mm}$ and corresponds to an expansion of the bandage of $\Delta \varepsilon=0,57 \%$. This expansion is smaller than the permissible expansion defined in Sect. 3.

\subsubsection{IM rotor}

In Fig. 11, the von Mises stress in the components of the IM is depicted for $n=0 \frac{1}{\mathrm{~min}}, 15000 \frac{1}{\mathrm{~min}}, 30000 \frac{1}{\mathrm{~min}}$ and $33000 \frac{1}{\mathrm{~min}}$. 


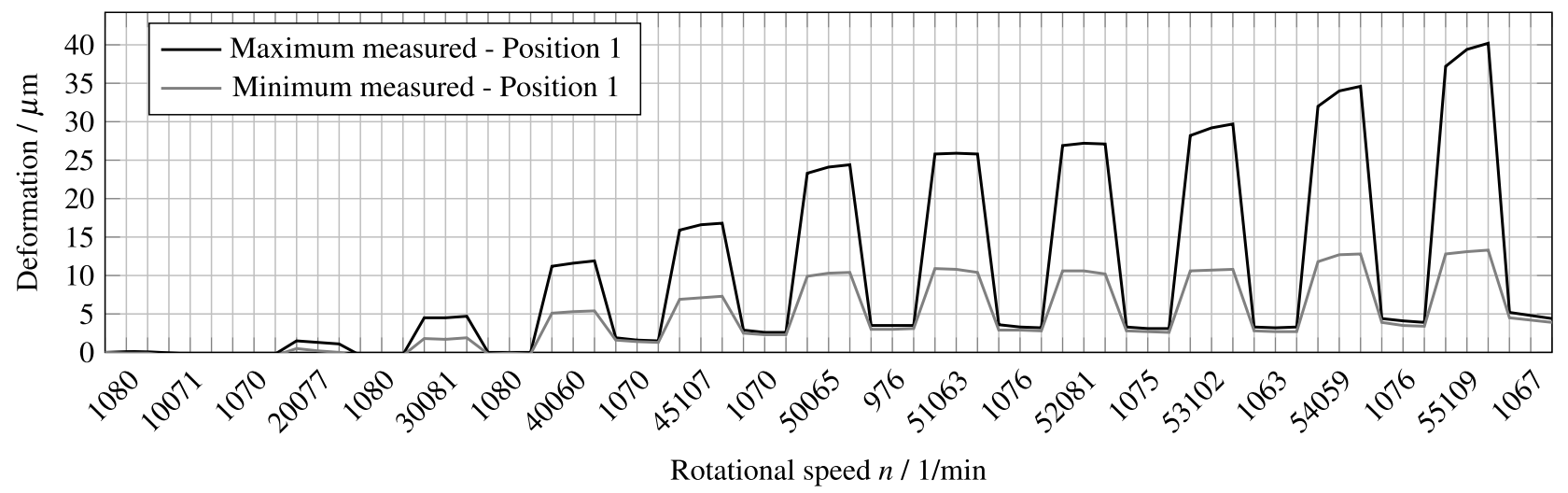

Fig. 12. Total deformations of the PMSM rotor measured at position 1 during the spin test

The influence of the press fit can be seen in Fig. 11 a). Due to the press fit, stress arises in particular in the yoke of the rotor lamination, the retaining ring and the short-circuit ring. The maximum mechanical stress in the rotor lamination is $\sigma_{\mathrm{VM}, R L, n_{0}}=370 \mathrm{MPa}$. The mechanical stress in the shaft increases slightly. In the copper bar, no change in the mechanical load can be seen.

When the rotor is accelerated, mechanical stress arises in the slot bridges and in the teeth of the rotor lamination and the retaining ring, as marked in Fig. 11 (d). The width of the slot bridge at the top of the copper bar is thinner than the tooth width, and accordingly, the mechanical stress in the slot bridge is significantly higher. The slot bridge is the crucial point in the rotor design. The mechanical stress in the short-circuit ring increases as well at the outer diameter. Though, the copper bar shows just a small mechanical load. The mechanical stress in the rotor lamination at maximum operational speed is $\sigma_{\mathrm{VM}, R L, n_{\max }}=420 \mathrm{MPa}$. In the retaining ring, the stress is higher and reaches $\sigma_{\mathrm{VM}, R R, n_{\max }}=440 \mathrm{MPa}$. The stress values are smaller than the maximum permissible mechanical stress defined by the safety factor and the yield strength of the used material in Sect. 3. At test speed, the mechanical stress in the rotor lamination increases up to $\sigma_{\mathrm{VM}, R L, n_{\text {spin }}}=480 \mathrm{MPa}$ and in the retaining ring up to

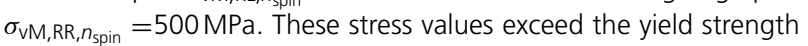
and already lead to a plastic deformation. The increase of the mechanical stress can be seen in Fig. 11 (b), (c) and (d).

\subsection{Surface deformation}

Now, the deformation measured during the spin test and the results of the simulation models are compared. First, the total deformation, including plastic and elastic deformation, measured in the spin tests is illustrated in Fig. 12 and Fig. 15. In Figs. 13, 14, 16 and 17 , the elastic deformation of the spin test and the simulation model are depicted. The measured elastic deformation is the difference between $n=1000 \frac{1}{\mathrm{~min}}$ and the examined rotational speeds $n$. The elastic deformation in the simulation model is the difference between the state of standstill and the examined rotational speed. The elastic deformation is plotted in a polar coordinate system around the circumference (see Fig. 13 and Fig. 16). The maximum and the minimum elastic deformation around the circumference are further depicted over the examined rotational speed steps (see Fig. 14 and Fig. 17).

\subsubsection{PMSM rotor}

The deformation at position 1 of the PMSM rotor during the spin test is shown in Fig. 12. The deformation increases with increasing speed. For rotational speed $n<40000 \frac{1}{\mathrm{~min}}$, the deformation is
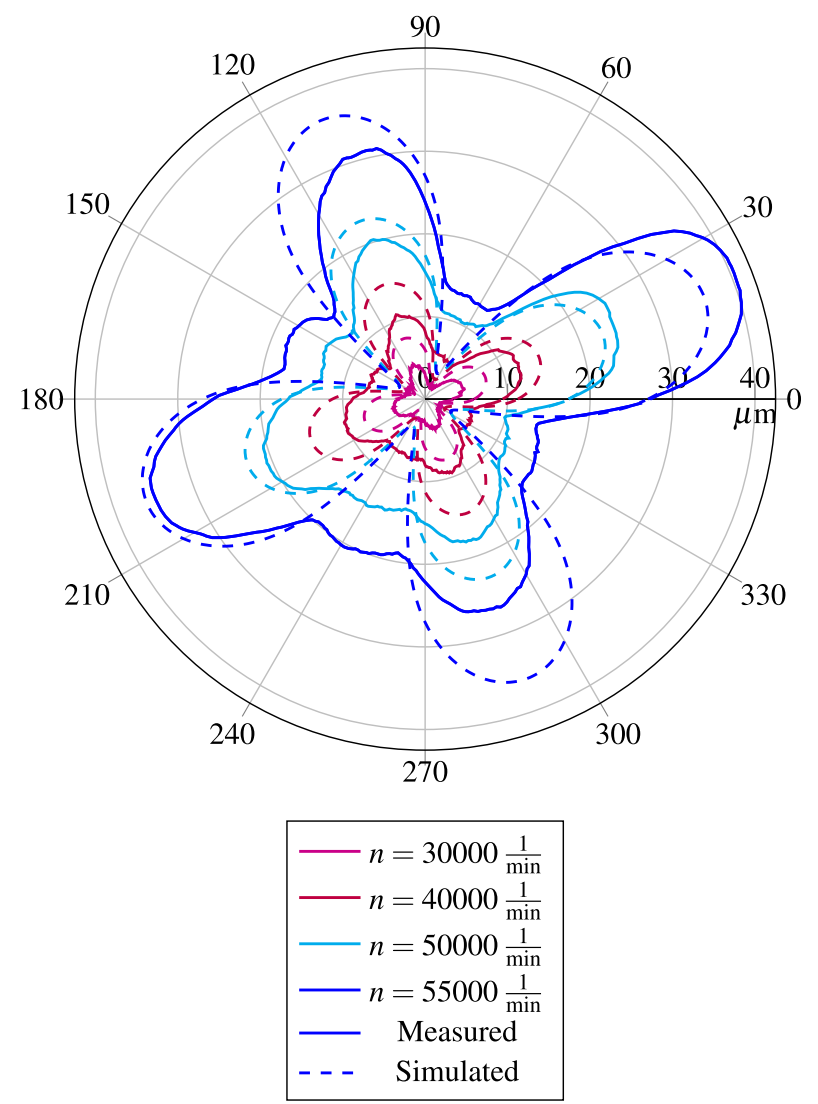

Fig. 13. Simulated and measured elastic deformations of the PMSM rotor versus circumferential position

elastic and the rotor returns to its initial state. At $n \geq 40000 \frac{1}{\mathrm{~min}}$, the deformation becomes plastic. A plastic deformation of $\varepsilon_{\mathrm{BA}, \mathrm{pl}}=$ $3 \ldots 5 \mu \mathrm{m}$ remains at the outer diameter of the rotor. The maximum deformation and the minimum deformation around the circumference are depicted. The maximum deformation appears above the magnets and the minimum deformation above the fill material. The minimum deformation increases up to $n=55000 \frac{1}{\min }$ and reaches a value of $\varepsilon_{B A, \min }=12 \mu \mathrm{m}$. The maximum deformation increases stronger and reaches $\varepsilon_{B A, \max }=40 \mu \mathrm{m}$. The measured plastic deformation cannot be calculated in the simulation model, since the material model is ideal and no residual plastic deformation is consid- 


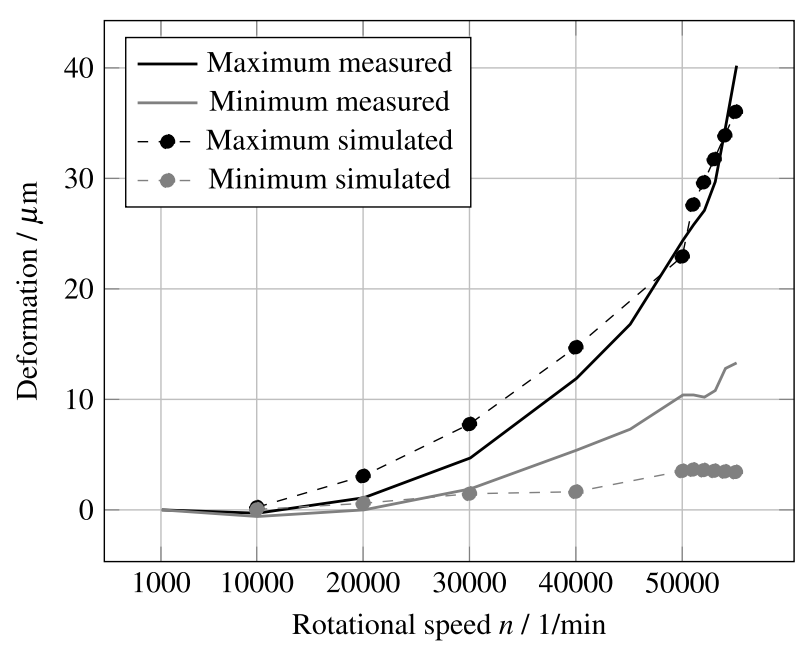

Fig. 14. Maximum and minimum elastic deformation of the PMSM rotor versus rotational speed

ered. The reason for this measured plastic deformation is an initial movement among the components during the spin test and the non-ideal material behaviour in the elastic area (see Sect. 2.2).

Elastic deformation in radial direction of the PMSM rotor is depicted in Fig. 13 as function of the circumference for four different rotational speeds. First, the deformation at the test speed is compared between the measurement and the simulation model. The measured deformation shows a different behaviour for the four poles of the rotor. The maximum deformation varies between $\varepsilon_{\mathrm{BA}, \text { max,el }}=40 \mu \mathrm{m}$ and $\varepsilon_{\mathrm{BA}, \min }=25 \mu \mathrm{m}$ and the shape of the deformation differs. The magnets are glued to the rotor lamination. The glue is used to fix the magnets before adding the fill material. The glue is not able to secure the magnets against centrifugal forces. Therefore, the bandage is added. As described in Sect. 5.1, the von Mises stress in the glue exceeds the ultimate strength at some positions and it can be assumed that there are local spots where the glue breaks. The difference in the deformation might occur due to this inaccuracy. Another reason might be an anisotropic material behaviour in the rotor lamination or in the bandage. It can be seen, that the poles opposing each other show a similar behaviour. The deformation in the simulation model is the same for the four poles, since the deformation is extracted using symmetry conditions without considering material anisotropy. For test speed and the max- imum operational speed, the maximum calculated deformation is close to the maximum measured deformation and the shape is reproduced well. For the speeds $n=40000 \frac{1}{\mathrm{~min}}$ and $n=30000 \frac{1}{\mathrm{~min}}$, the calculated and the measured deformation show some deviations in amplitude. The deformation is calculated higher as it actually is. Though, the deformation is mapped well. The deviation between the measurement results and the simulation model might occur due to the modelling of the glue between the magnet and the rotor lamination. In [16], the influence of the glue is analysed for a PMSM with buried magnets and a strong impact on the deformation can be noticed. If the model used here for the surface-mounted PMSM is simulated without the glue and a frictional or bonded contact between the rotor lamination and the magnet is used, the deformations are significantly smaller. Accordingly, the expansion behaviour for the model without glue is not capable to reproduce the actual behaviour of the rotor. The magnets are also kept at the rotor lamination due to magnetic forces between the magnet and the rotor lamination. These forces are not considered in the simulation model and should be analysed more in details.

The deviation can be seen as well in Fig. 14, where the maximum and the minimum elastic deformations are depicted over the speed. The deviation between the simulated deformation and the measured deformation between $n=10000 \frac{1}{\mathrm{~min}}$ and $n=45000 \frac{1}{\mathrm{~min}}$ can be seen here as well. Though it must be said, that the deviation shown in Fig. 14 appears to be large, since the maximum deformation of the pole at $\phi=30^{\circ}$ is depicted, which shows a higher deformation than the other poles.

To sum up, the measurement and the simulation model show good accordance. In the measurements themselves, we can observe a different deformation for the four poles. Thus, the comparison with the simulation model is difficult. Further, the simulation model shows a slightly higher deformation than the measurements. The deformation depends strongly on the modelling of the glue between magnet and rotor lamination. The simulation model is suitable to evaluate the maximum elastic mechanical stress and the deformation of the PMSM rotor.

\subsubsection{IM rotor}

The measured deformation of the IM rotor is depicted in Fig. 15 for positions 1 and 2 . The deformation increases quadratic with the speed. At position 2, the deformation is higher than the deformation at position 1. This can be seen especially for higher rotational speeds. The short-circuit ring and the copper bar expand further than the rotor lamination. At the maximum operating speed, the

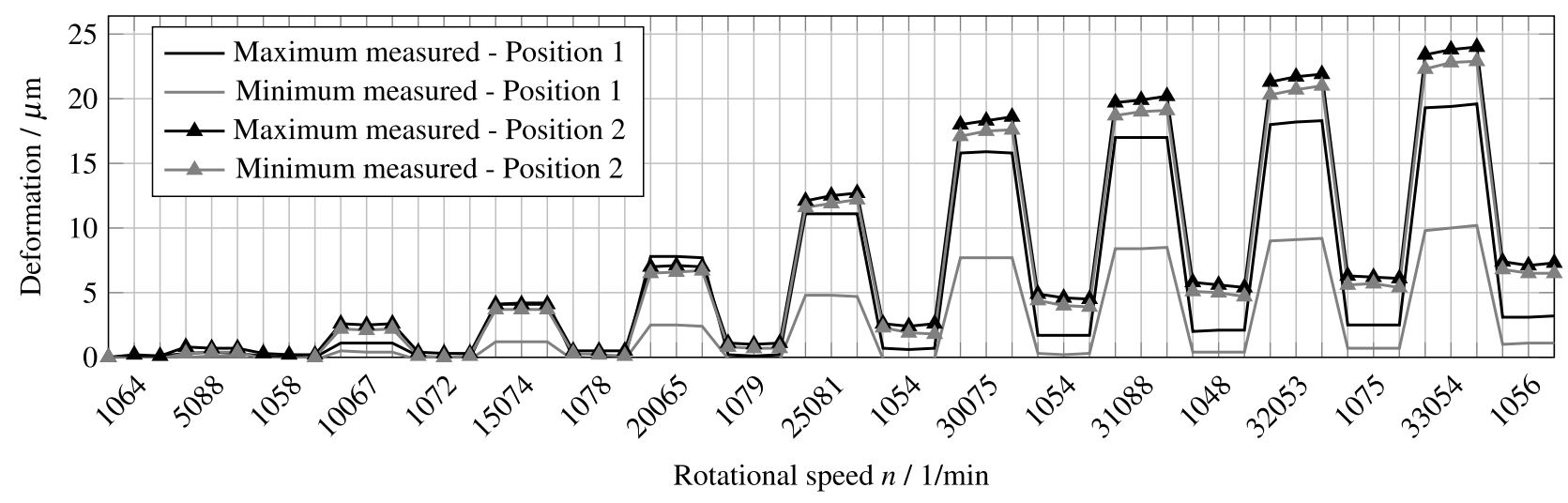

Fig. 15. Total deformations of the IM rotor measured at positions 1 and 2 during the spin test 
deformation at position 1 is $\varepsilon_{n_{\max }, \mathrm{RL}}=16 \mu \mathrm{m}$, whereas the deformation at position 2 is $\varepsilon_{n_{\max }, \mathrm{SC}}=18,8 \mu \mathrm{m}$. The deformation occurs even if the mechanical stress in the rotor lamination is higher than in the short-circuit ring. The copper bars are inserted in the rotor lamination and in the retaining ring. Due to the production process, there is some space between them. They are not pressed into each other, as for example the press fit between shaft and rotor lamination. The short-circuit ring is placed between the rotor lamination and the retaining ring. Thus, the short-circuit ring and the copper bar can move within the rotor lamination and the retaining ring. Therefore, they expand further than the rotor lamination whereas the mechanical stress is smaller. Above $n>20000 \frac{1}{\mathrm{~min}}$, the deformation becomes plastic. The rotor does not return to its initial state when the rotor is decelerated. The plastic deformation in the rotor lamination is $\varepsilon_{n_{\max }, \mathrm{RL}, \mathrm{pl}}=2 \mu \mathrm{m}$ and in the short-circuit ring $\varepsilon_{n_{\max }, \mathrm{SC}, \mathrm{pl}}=4,6 \mu \mathrm{m}$. The reason for this plastic deformation might be the non-ideal material behaviour in the elastic area (see Sect. 2.2) and an initial movement among the components during the spin test.

In Fig. 16, the elastic deformation of the IM rotor is shown in a polar plot over the circumference. The results of the simulation model are compared to the measurement results. First, the deformation at position 1 is described and analysed. The influence of the copper bars and the rotor slots can be seen in the measurements and the simulation. Due to the rotation, the copper bars are pressed to the slot bridges of the rotor lamination and lead to a significant deformation up to $\Delta \varepsilon=5 \mu \mathrm{m}$. The measured deformation changes significantly around the circumference. At $\phi=160^{\circ}, \phi=260^{\circ}$ and $\phi=310^{\circ}$, the deformation is significantly smaller. It can be assumed that the copper bars are better bonded to the rotor lamination at these positions due to the brazing in the production process. This effect might cause an eccentricity and imbalance on the rotor. This effect is not regarded in the simulation model of the IM rotor, where the connections between the copper bars and the rotor lamination are set to be frictionless. The simulation model is reduced to a 1/30 of the rotor geometry, based on the assumption that the rotor has a symmetric behaviour for the 30 rotor slots (see Sect. 3.1)). Accordingly the deformation repeats uniformly around the circumference in the simulation. Even if the simulated and the measured deformation around the circumference show some deviations, the maximum simulated deformation of $\varepsilon_{\mathrm{el}, \mathrm{sim}}=20,5 \mu \mathrm{m}$ fits well with the maximum measured deformation $\varepsilon_{\mathrm{el}}$, meas $=20,1 \mu \mathrm{m}$. Thus, the highest deformation in the crucial part of the rotor, the slot bridges, is represented in the calculation, allowing a statement concerning the robustness of the rotor lamination.

In Fig. 16 (b), the deformation at position 2 at the short-circuit ring is depicted. The influence of the copper bars is less distinct in the measurement results than at position 1. The short-circuit ring and the copper bars expand together, and the short-circuit ring does not secure the copper bars as strongly as the rotor lamination. In the simulation model, this effect is not considered. The influence of the copper bars on the short-circuit ring is as strong as in position 1. But the magnitude of the deformation fits to the measurement results and describes the expansion of the IM rotor well.

In Fig. 17 (a), the maximum and the minimum elastic deformation of the measurement and the simulation model are plotted over the rotational speed for position 1. The maximum simulated and measured deformations show a good accordance for the examined speed range. The minimum simulated elastic deformation shows a high deviation between measurement and simulation. These deviations have been explained earlier and are due to the bonding of the copper bars and the rotor lamination. This deviation is significantly smaller at position 2 . The measured minimum and maximum elastic

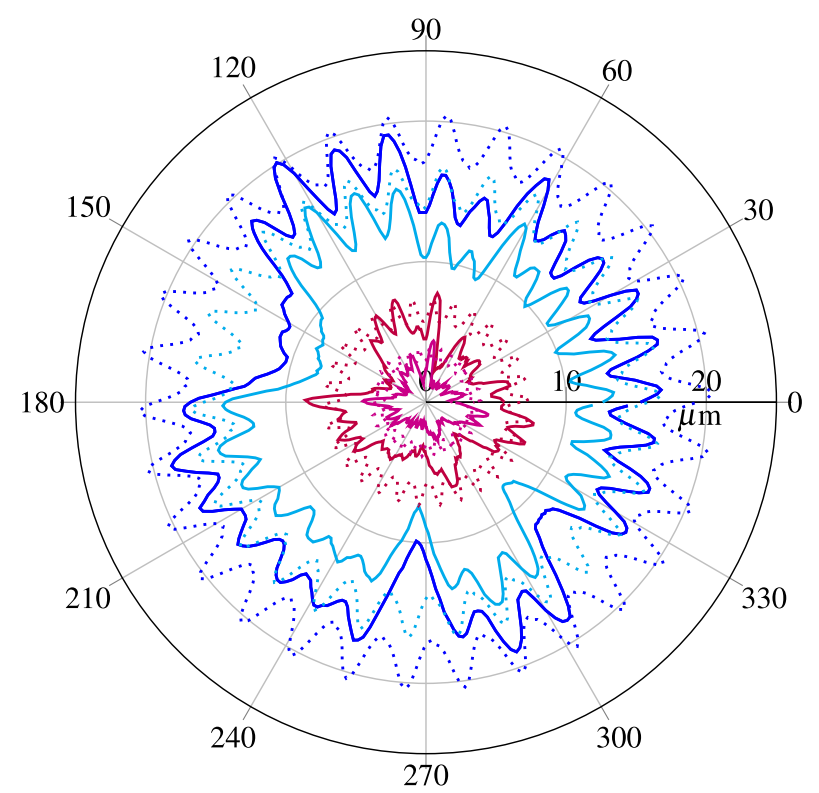

(a) Position 1: Axial middle of the rotor.
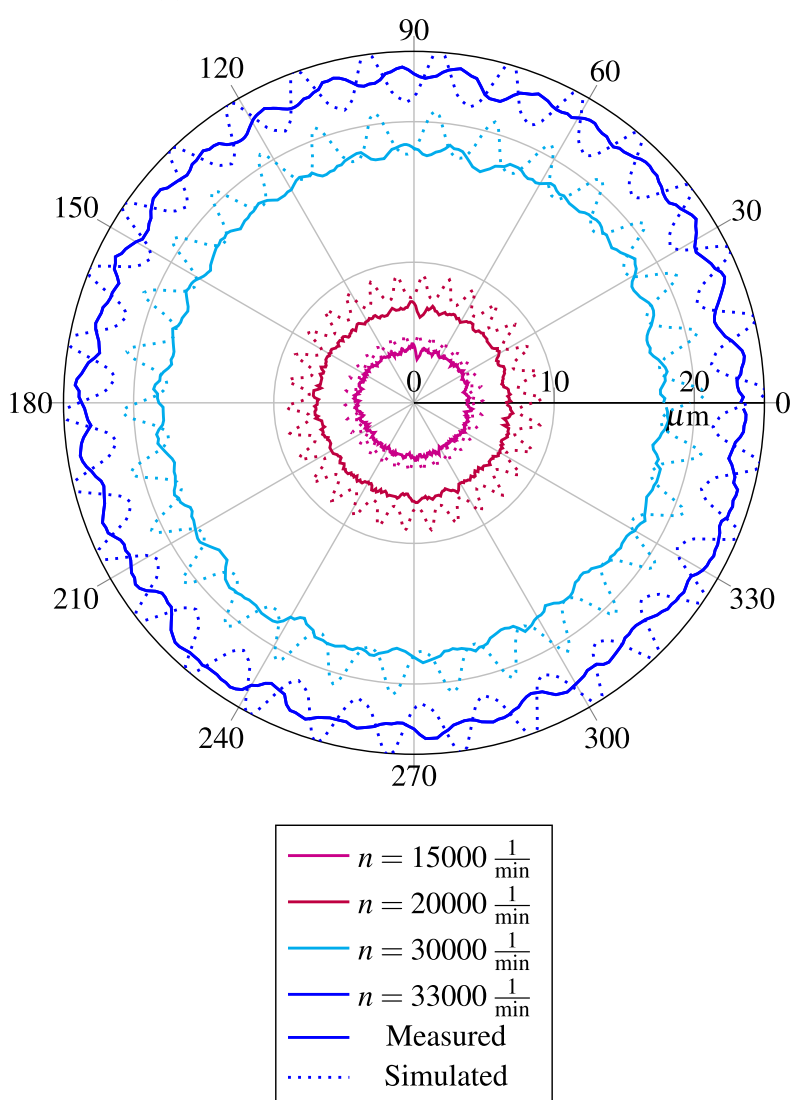

(b) Position 2: Middle of the short circuit ring.

Fig. 16. Simulated and measured elastic deformation of the IM rotor versus circumferential position

deformations of the short-circuit ring are within the range of the simulated values.

Overall, the simulation model shows a good accordance with the measurements and is suitable for evaluating the maximum elastic mechanical stress of the IM rotor. 


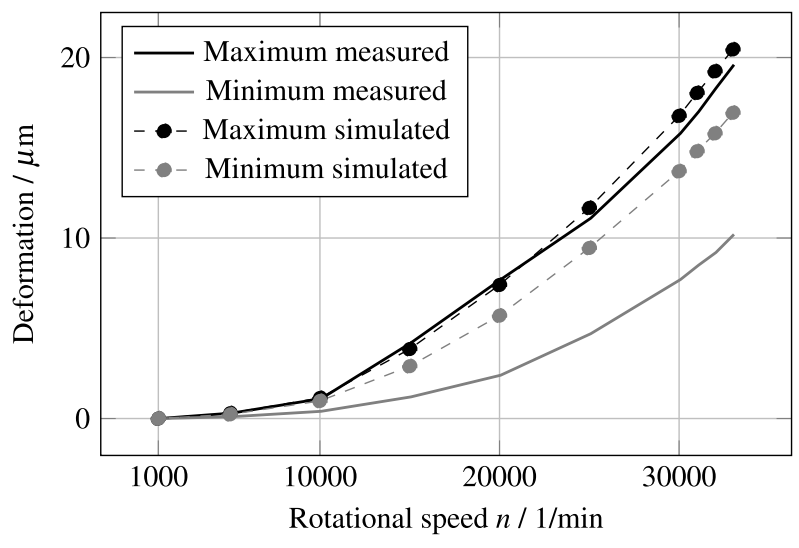

(a) Position 1: Axial middle of the rotor.

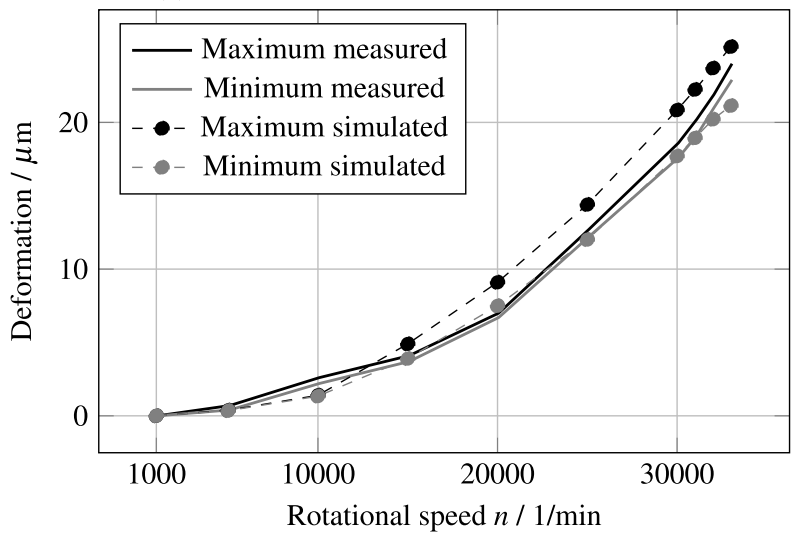

(b) Position 2: Middle of short circuit ring.

Fig. 17. Maximum and minimum elastic deformations of the IM rotor versus rotational speed

Table 7. Results of the burst test of PMSM rotor

\begin{tabular}{llll}
\hline Rotor & $\begin{array}{l}\text { Max. rotational } \\
\text { speed } n_{\text {burst }}\end{array}$ & $\begin{array}{l}\text { Termination } \\
\text { criterion }\end{array}$ & Comments \\
\hline PMSM & $62982 \frac{1}{\min }$ & $\begin{array}{l}\text { Max. speed of } \\
\text { gearbox }\end{array}$ & $\begin{array}{l}\text { No visible } \\
\text { deformation }\end{array}$ \\
Rotor 1 & & $\begin{array}{l}\text { Max. speed of } \\
\text { gearbox }\end{array}$ & $\begin{array}{l}\text { No visible } \\
\text { deformation }\end{array}$ \\
PMSM & $62990 \frac{1}{\min }$ & & \\
Rotor 2 & & & \\
\hline
\end{tabular}

\subsection{Burst tests}

In this section, the results of the burst test are presented for the PMSM rotors and then for the IM rotors.

\subsubsection{PMSM rotor}

The results of the burst test for the PMSM rotors are presented in Table 7. Both rotors are accelerated up to $n=63000 \frac{1}{\mathrm{~min}}$ without failure by burst. The maximum speed of $n=63000 \frac{1}{\mathrm{~min}}$ was limited by the axle box of the spin test machine. This speed is $114 \%$ of the defined test speed. No deformation or destruction were visible after conducting the burst test.

\subsection{2 $1 \mathrm{M}$ rotor}

In Table 8, the results of the burst test of the IM rotor are given. The first rotor failed at $n=52400 \frac{1}{\mathrm{~min}}$, which is $157 \%$ of the defined test speed due to bursting. The bursted rotor lamination, parts of

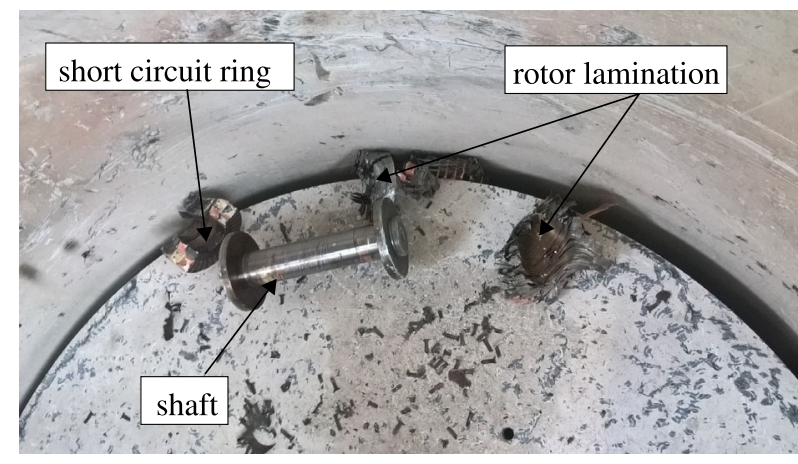

(a) Bursted IM rotor and shaft.

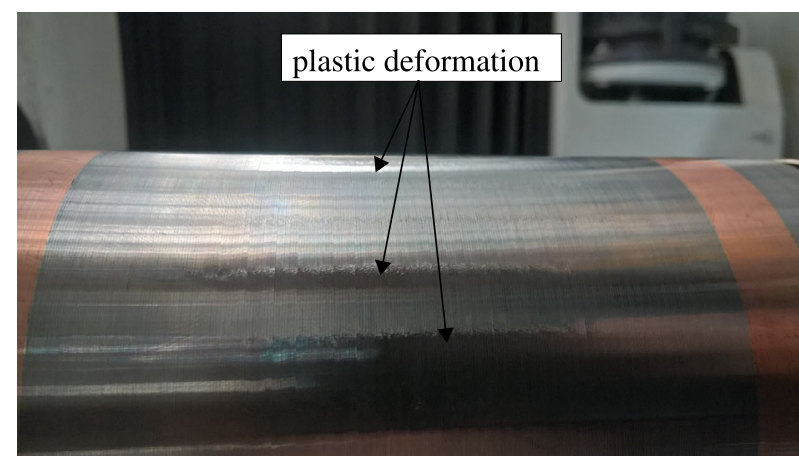

(b) Deformed IM rotor.

Fig. 18. Results of the burst test IM

Table 8. Results of the burst test of IM rotor

\begin{tabular}{|c|c|c|c|}
\hline Rotor & $\begin{array}{l}\text { Max. rotational } \\
\text { speed } n_{\text {burst }}\end{array}$ & $\begin{array}{l}\text { Termination } \\
\text { criterion }\end{array}$ & Comments \\
\hline $\begin{array}{l}\text { IM } \\
\text { Rotor } 1\end{array}$ & $52402 \frac{1}{\mathrm{~min}}$ & Burst of rotor & $\begin{array}{l}\text { Destruction of } \\
\text { the lamination } \\
\text { sheet }\end{array}$ \\
\hline $\begin{array}{l}\text { IM } \\
\text { Rotor } 2\end{array}$ & $51874 \frac{1}{\min }$ & $\begin{array}{l}\text { Shaft } \\
\text { vibrations }\end{array}$ & $\begin{array}{l}\text { Strongly } \\
\text { deformed rotor, } \\
\text { shape of the } \\
\text { bars visible }\end{array}$ \\
\hline
\end{tabular}

the copper bars and the shaft can be seen in Fig. 18 (a). The rotor components are completely destroyed and it became apparent that a high amount of energy was stored in the material. The second rotor had to be stopped at $n=51700 \frac{1}{\mathrm{~min}}$ due to high shaft vibrations. The shaft vibration might be caused by the eccentricity of the rotor bars (see Sect. 5.2). The analysed rotor is depicted in Fig. 18 (b). Strong plastic deformations become evident at the slot bridges where the copper bars press on the rotor lamination.

\section{Conclusion}

In this work, the mechanical load on a PMSM rotor and on a IM rotor of a high speed electric machine are examined. The mechanical stress and the deformation are examined, using two FEM simulation models. The results are compared to the measurements of a spin test. During the spin test, the deformation at the surface of the rotors is measured. Additionally, four burst tests of the examined rotors are performed. 
The mechanical stress in the rotors is analysed using the von Mises stress and compared to the yield strength of the used materials. In both rotors, the maximum permissible stress in the used materials is not exceeded for $n<n_{\max }$. For the test speed, the mechanical stress in the rotor lamination of the IM rotor is close to the yield strength.

During the spin test, plastic deformation at the rotor surface can be observed for both rotor types. The deformation occurs possibly due to initial movement during the first run-up and due to a nonlinear material behaviour in the elastic area.

The deformation at the rotor surface is depicted around the circumference for different rotational speeds. In the measurements, a behaviour varying around the circumference can be observed for the two rotor types. The PMSM rotor shows different deformations for the four poles. The maximum deformation at the test speed varies from $\varepsilon_{\mathrm{BA} \text {,max,el }}=25 \mu \mathrm{m}$ to $\varepsilon_{\mathrm{BA} \text {,max,el }}=40 \mu \mathrm{m}$. This deviation is possibly due to the different glue connection of the magnets and the rotor lamination. At the rotor lamination of the IM rotor, the deformation changes as well. Some copper bars are connected better to the rotor lamination than others. The deformation at the test speed varies from $\varepsilon_{\mathrm{RL} \text {,max,el }}=12 \mu \mathrm{m}$ to $\varepsilon_{\mathrm{BA} \text {, max,el }}=20 \mu \mathrm{m}$. The measured deformation is compared to the calculated deformation of the FEM models.

The calculation model of the PMSM shows some deviations compared to the measurements. For the speed range of $10000 \frac{1}{\mathrm{~min}}<$ $n<45000 \frac{1}{\min }$, the deformation of the calculation model is slightly higher than the deformation in the measurement. At maximum operating speed, and at the test speed, the deformation fits the measurement results well. Overall, the shape of the deformation can be reproduced in the calculation model. It can be concluded, that the simulation model can be used to evaluate the mechanical stress and the deformation of the PMSM rotor.

The calculated deformation of the IM rotor reproduces the measurement in the spin test. The deformations calculated at the rotor lamination and at the short-circuit ring match the maximum deformation of the measurement. The shape of the rotor bars pressing to the rotor lamination can be recognized in the simulation model and in the measurements. The simulation model is capable of describing the mechanical stress and the deformation in the IM rotor.

The measurements and the simulation are carried out at the ambient temperature of $T=20^{\circ} \mathrm{C}$ due to the predefined criteria of the spin test. Though, the temperature has a strong impact on the deformation and accordingly to the mechanical stress in the rotor. This influence needs to be determined in more details in future works.

Finally, the results of the burst test are presented. The two rotor specimen of the IM rotor reach rotational speeds that are $70 \%$ higher than the maximum operating speed. The two PMSM rotors withstand the centrifugal forces up to more than $25 \%$ of the maximum operating speed. A burst could not be reached due to the limited maximum speed of the spin test machine.

Funding Note Open Access funding enabled and organized by Projekt DEAL.

Publisher's Note Springer Nature remains neutral with regard to jurisdic tional claims in published maps and institutional affiliations.

Open Access Dieser Artikel wird unter der Creative Commons Namensnennung 4.0 International Lizenz veröffentlicht, welche die Nutzung, Vervielfältigung, Bearbeitung, Verbreitung und Wiedergabe in jeglichem Medium und Format erlaubt, sofern Sie den/die ursprünglichen Autor(en) und die Quelle ordnungsgemäß nennen, einen Link zur Creative Commons Lizenz beifügen und angeben, ob Änderungen vorgenommen wurden. Die in diesem Artikel enthaltenen Bilder und sonstiges Drittmaterial unterliegen ebenfalls der genannten Creative Commons Lizenz, sofern sich aus der Abbildungslegende nichts anderes ergibt. Sofern das betreffende Material nicht unter der genannten Creative Commons Lizenz steht und die betreffende Handlung nich nach gesetzlichen Vorschriften erlaubt ist, ist für die oben aufgeführten Weiterverwendungen des Materials die Einwilligung des jeweiligen Rechteinhabers einzuholen. Weitere Details zur Lizenz entnehmen Sie bitte der Lizenzinformation auf http://creativecommons.org/licenses/by/4.0/deed.de.

\section{References}

1. Narjes, G., Muller, J., Mertens, A., Ponick, B., Kauth, F., Seume, J. (2016): Design considerations for an electrical machine propelling a direct driven turbo compressor for use in active high-lift systems. In ESARS-ITEC international conference on electrical systems for aircraft, railway, ship propulsion and road vehicles \& international transportation electrification conference (pp. 1-8). New York: IEEE.

2. Paulides, J., Encica, L., Beernaert, T. F. (2015): Ultra-light-weight high torque density brushless pm machine design: considering driving-cycle of a four-wheel drive race car In 2015 10th international conference on ecological vehicles and renewable energies (EVER) (pp. 1-7). New York: IEEE.

3. Zhitkova, S., Felden, M., Franck, D., Hameyer, K. (2014): Design of an electrical motor with wide speed range for the in-wheel drive in a heavy duty off-road vehicle. In International conference on electrical machines (ICEM), 2014 (pp. 1076-1082).

4. El-Refaie, A., Osama, M. (2017): High specific power electrical machines: a system perspective. In 2017 20th international conference on electrical machines and systems (ICEMS) (pp. 1-6). New York: IEEE.

5. Wiesemann, J., Sommer, C., Mertens, A. (2019): Switching characteristics of a 1.2 $\mathrm{kV}$ sic mosfet module using a controllable current-sourced gate driver. In PCIM Europe 2019; international exhibition and conference for power electronics, intelligent motion, renewable energy and energy management, (pp. 1466-1471). Berlin: VDE Verlag.

6. Merkert, A., Krone, T., Mertens, A. (2012): Characterization and scalable modeling of power semiconductors for optimzied design of traction inverters with si- and sicdevices. In IEEE vehicle power and propulsion conference (VPPC), 2012 (pp. 647-652). New York: IEEE.

7. Gerada, D., Mebarki, A., Brown, N. L., Gerada, C., Cavagnino, A., Boglietti, A. (2014): High-speed electrical machines: technologies, trends, and developments. IEEE Trans. Ind. Electron., 61(6), 2946-2959.

8. Borisavljevic, A., Polinder, H., Ferreira, J. A. (2010): On the speed limits of permanentmagnet machines. IEEE Trans. Ind. Electron., 57(1), 220-227.

9. Binder, A., Schneider, T. (2007): High-speed inverter-fed ac drives. In 2007 international Aegean conference on electrical machines and power electronics (ACEMP) and electromotion '07 (pp. 9-16)

10. Li, S., Li, Y., Choi, W., Sarlioglu, B. (2016): High-speed electric machines: challenges and design considerations. IEEE Trans. Transp. Electrif., 2(1), 2-13.

11. Boglietti, A., Cavagnino, A., Tenconi, A., Vaschetto, S. (2010): Key design aspects of electrical machines for high-speed spindle applications. In IECON 2010 (pp. 17351740). New York: IEEE.

12. Gong, C., Habetler, T. (2017): A novel rotor design for ultra-high speed switched reluctance machines over 1 million rpm. In 2017 IEEE international electric machines and drives conference (IEMDC) (pp. 1-6). New York: IEEE.

13. Liu, G., Qiu, G., Zhang, F., Qiu, F., Cao, W. (2016): Outer rotor mechanical and dynamic performance analysis for high-speed machine. In ITEC 2016 (pp. 509-513). New York: IEEE.

14. Matsumoto, Y., Miki, I., Morinaga, K. (2013): Study on ipmsm with ferrite magnets driven at high speeds. In 2013 international conference on electrical machines and systems (ICEMS) (pp. 1064-1067). New York: IEEE.

15. Enno Gerlach, M., Zajonc, M., Ponick, B. (2020): Methodology to evaluate the mechanical stress in high speed electric machines with buried magnets. In 2020 international symposium on power electronics, electrical drives, automation and motion (SPEEDAM) (pp. 77-84). New York: IEEE.

16. Karthaus, J., Hameyer, K. (2017): Static and cyclic mechanical loads inside the rotor lamination of high-speed pmsm. In 2017 7th international electric drives production conference (EDPC) (pp. 1-6). New York: IEEE.

17. Hosford, W. F. (2009): Mechanical behavior of materials. Cambridge: Cambridge University Press.

18. Dowling, N. E. (2013): Mechanical behavior of materials: engineering methods for deformation, fracture, and fatigue. 4. ed. Boston: Pearson.

19. Leisure, R. G. (2017): Ultrasonic spectroscopy. Cambridge: Cambridge University Press.

20. Gottstein, G. (2014): Materialwissenschaft und Werkstofftechnik: Physikalische Grundlagen. 4. ed. Berlin: Springer.

21. Gordon Budynas, R., Nisbett, J. K., Shigley, J. E. (2011): Shigley's mechanical engineering design. In McGraw-Hill series in mechanical engineering. 9. ed. New York: McGraw-Hill.

22. Weichert, D. Festigkeitslehre: Mechanik 2 für ingineure. 2010

23. Schürmann, H. (2007): Konstruieren mit Faser-Kunststoff-Verbunden. VDI-Buch. 2. ed Berlin Heidelberg: Springer 
24. Volker, L. (2016): Einführung in die Festigkeitslehre. Wiesbaden: Springer Fachmedien Wiesbaden.

25. Prescott, J. (1961): Applied elasticity. New York: Dover Publications, INC

26. ANSYS (2010): Customer training material: ansys mechanical structural nonlinearities: Lecture 3 - introduction to contact.

27. Lee, H.-H. (2018): Finite element simulations with ANSYS workbench 19. Mission, KS: SDC Publications.

28. Gebhardt, C. (2014): Praxisbuch FEM mit ANSYS Workbench: Einführung in die lineare und nichtlineare Mechanik. 2. ed. München: Hanser

29. Yagawa, G., Matsubara, H. (2007): Enriched free mesh method: an accuracy improvement for node-based fem. In E. Oñate, R. Owen (Eds.), Computational plasticity. Computational methods in applied sciences (Vol. 7, pp. 207-219). Netherlands, Dordrecht: Springer

30. DEW Stahl: Werkstoffdatenblatt 34CrNiMo6 1.6582. https://www.dew-stahl.com/ fileadmin/files/dew-stahl.com/documents/Publikationen/Werkstoffdatenblaetter/. [9.12.2020].

\section{Authors}

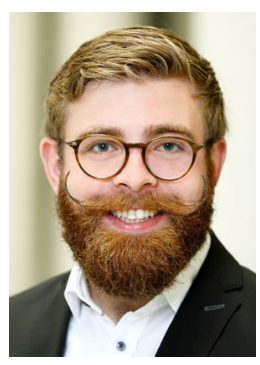

\section{Martin Enno Gerlach}

was born in Hannover, Germany, in 1992. In 2017, he graduated with a Master of Science in electrical engineering at the RWTH Aachen University. After completing his studies, he started working as a research associate at the Institute for Drive Systems and Power Electronics, Leibniz University Hannover in December 2017. His main research is in the fields of vibration and acoustics of electric machines and the mechanical design and prediction of high speed electric rotors.

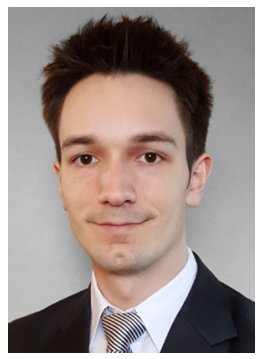

\section{Maximilian Zajonc}

was born in Salzgitter, Germany, in 1991. In 2019, he graduated with a Master of Science in electrical engineering at the Leibniz University Hannover. After completing his studies he started working as a R\&D engineer at ZF Friedrichshafen AG in Friedrichshafen in May 2019. His main activities are simulation and evaluation of new technologies for electrica machines.

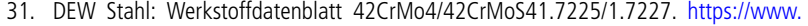
dew-stahl.com/fileadmin/files/dew-stahl.com/documents/Publikationen/ Werkstoffdatenblaetter/. [9.12.2020].

32. Henkel (2004): Technisches Datenblatt Loctite 326. https://www.silitech.ch/upload/. [9.12.2020]

33. Bomatec (2015): BMSG-32H Sm2C017. https://www.bomatec.com/wp-content/uploads/. [9.12.2020]

34. Huntsman (2004): Araldite AV 4415 / Hardener HV 4416: Two component epoxy paste adhesive for pipe bonding https://www.bag-distribution.com/Files/. [9.12.2020].

35. Cogent Surahammars Bruks AB (2008): Typical data for SURA M250-35A. https:/l www.tatasteeleurope.com/ts/automotive/products/electrical-steel. [9.12.2020].

36. van der Giet, M., Kasper, K., de Doncker, R. W., Hameyer, K. (2012): Material parameters for the structural dynamic simulation of electrical machines. In 2012 XXth international conference on electrical machines (pp. 2994-3000). New York: IEEE.

37. Deutsches Kupferinstitut. CuCr1Zr. https://www.kupferinstitut.de/wp-content/. 9.12.2020.

38. Deutsches Kupferinstitut. Cu-ETP https://www.kupferinstitut.de/wp-content/. [9.12.2020]

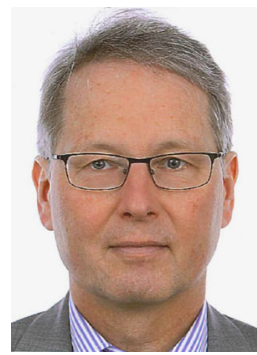

\section{Bernd Ponick}

was born in Großburgwedel, Germany, in 1964. He received his Dipl.-Ing. degree in electrical power engineering from the University of Hannover in 1990 and his Dr.-Ing. degree for a thesis on electrical machines in 1994. After 9 years with the Large Drives Division of Siemens as design engineer for large variable speed motors, head of electrical design and Technical Director of Siemens Dynamowerk Berlin, he is since 2003 full professor for electrical machines and drive systems at Leibniz University Hannover. His main research activities are calculation and simulation methods for electrical machines, prediction of and measures against important parasitic effects such as magnetic noise, additional losses or bearing currents, and new applications for electric machines, e.g. for electric and hybrid vehicles or for aviation. 